\title{
LA CONSTITUCIONALIZACIÓN EUROPEA Y LAS CONSTITUCIONES DE PORTUGAL Y DE ESPAÑA*
}

\author{
POR \\ JOSÉ LUIS PRADA FERNÁNDEZ DE SANMAMED \\ Profesor Titular de Universidad de Derecho Constitucional \\ Universidad de La Laguna
}

Constituye un honor empezar la colaboración en La Revista de Derecho Político de la Universidad Nacional de Educación a Distancia. Vaya, pues, por delante nuestro profundo agradecimiento a su Consejo

\begin{abstract}
* Es esta una línea de investigación de derecho constitucional comparado que llevamos desarrollando desde hace tiempo y que ha demostrado exigir una constante actualización. Pretendimos llamar la atención sobre ella con la comunicación presentada en la Ponencia General sobre «Derecho Constitucional y Derecho Comunitario", del XIV Congreso de la Asociación Española de Derecho Constitucional, celebrado el 28 y 29 de abril de 1999 en la Universidad de Alicante, trabajo publicado íntegramente como "Tendencias de la convergencia constitucional europea en las reformas institucionales italianas", Anales de la Facultad de Derecho, Universidad de La Laguna (en adelante, Anales), 17, 2000, pp. 241-265; en este trabajo se contemplaba la convergencia en seis Estados de la Unión con ocasión del Tratado de Maastricht. La actualización de la dimensión de la convergencia de Latinoeuropa también nos ha preocupado en "Análisis comparado de las últimas reformas y leyes constitucionales en Europa sudoccidental», Anales, 20, 2003, pp. 183-214, y en la comunicación "La Convergencia Constitucional en Europa Latina tras la clausura de la Convención Europea (verano de 2003)", presentada al VIII Congreso Iberoamericano de Derecho Constitucional, celebrado en la Universidad de Sevilla (y editada en Cd-Rom), en que utilizamos como marco de referencia comparatista cuatro Estados
\end{abstract}


de Redacción en el cual contamos con entrañables amigos y a las autoridades académicas de la U.N.E.D. Consejo de Redacción que se ha permitido el tratamiento de la cuestión de la constitucionalización europea en unos momentos de europesimismo y en los que hace falta la colaboración de todos, en la más adecuada construcción de Europa.

\section{LA CRISIS DE 2005 DE LA CONSTITUCIONALIZACIÓN EUROPEA}

Antes de nada, es preciso fijar la naturaleza jurídica de la llamada Constitución Europea y dar cuenta de los aconteceres de su proceso de ratificación.

\section{1. ¿Tratado constitucional o Constitución europea?}

En los foros académicos europeos la primera de las discusiones se centraba en si el "Proyecto de Tratado por el que se establece una Constitución para Europa, firmado en Roma (PTCR)" era nada más que otro Tratado constitucional, un elemento constitutivo más de la progresiva constitucionalización europea, o era la auténtica Constitución de la Europa ampliada a 25 Estados miembros. Es de advertir que en este debate había mucho de recelo entre ramas jurídicas y especialmente entre internacionalistas, comunitaristas y constitucionalistas. Por nuestra parte, como constitucionalista, seguiremos sin rubor las pautas generales del prestigioso Profesor de la Universidad de Coimbra Gomes Canotillo, según una relación dictada en la Universidad de Sevilla en diciembre de 2003 en el seno del VIII Congreso Iberoamericano de Derecho Constitucional — pendiente de publicación- y, por consiguiente, nos atenazarán los exigentes pruritos del constitucionalismo que nos llevan a negar al Tratado el carácter de una auténtica Constitución. Esta negativa obedece a varias razones.

En primer lugar, porque en la tradición político-constitucional europea primero fue el Estado y bastante después la Constitución y todavía más tardío el Estado Constitucional, de tal modo que - sin negar la posibilidad de una Constitución fundada en un Tratado- por regla gene-

miembros y las modificaciones de los Tratados de Amsterdam y de Niza; por último, hemos revisado nuestros planteamientos en Convergencia y divergencias constitucionales en la Europa Ibérica (publicación del Aula Magna del curso 2004 de la Faculdade de Direito) Curitiba, Universidade Federal do Paraná- CEJUR- CAHS, marzo de 2004, 40 pp. 
ral lo que necesita cualquier Constitución es de un Estado que al tiempo que lo regula (o limita) es sustentado por él, y, lo cierto, es que en Europa siguen siendo los Estados nacionales los que monopolizan la fuerza, el poder político y la soberanía. A pesar de que el art. I.7 del PTCR reconoce por fin que la Unión tiene una única personalidad jurídica, en el caso de la ratificación del Tratado estaríamos ante una mera Unión de Estados de probable carácter confederal pero totalmente dependiente de los designios de los Estados miembros ${ }^{1}$.

En segundo lugar, en la aprobación del Tratado no se dieron las exigencias actuales de un poder constituyente. Se recordará que el Proyecto fue redactado por una Convención europea formada por delegados de los Estados miembros con una abierta participación, aunque luego fue sometido a una Conferencia Intergubernamental (CIG) y, por último firmado por unanimidad, por el Consejo Europeo de Roma de Jefes de Estado y de Gobierno. Lo cierto es que el pueblo europeo no ha sido consultado, ni en su totalidad, ni en un referéndum conjunto que sería lo deseable. Estas críticas se pueden reproducir con respecto al procedimiento de reforma previsto en el PTCR, dado que sigue siendo un procedimiento internacional, pues, como en la aprobación del Tratado, el papel decisivo lo asumen los Estados miembros.

Si se atiende a las competencias exclusivas de la Unión que se determinan en el art. I-12 del PTCR, el proyecto de Tratado no es más que la regulación de la Unión Económica y Monetaria y del Mercado Común, y fijándonos en su conjunto es una rudimentaria Constitución política, mientras que las Constituciones de hoy en día deben ser también sociales, económicas, de defensa y de seguridad exterior e interior.

Por último, los Estados nacionales de la Europa de hoy son una "Comunidad de derechos fundamentales constitucionalmente reconocidos y garantizados" (especialmente de los derechos sociales). Por el contrario, a pesar de que en el Tratado abundan las referencias a los derechos fundamentales, esta abundancia ha sido calificada de "meta-narrativa", dado que no se genera una Comunidad europea de derechos fundamentales, salvo los consagrados en el Convenio de Roma de derechos y libertades públicas, y lo que sigue existiendo son las respectivas Comunidades nacionales de derechos.

En definitiva concluimos con parecidos términos a los del Profesor Gomes Canotillo, para el constitucionalista con el PTCR estamos ante una pseudo-Constitución europea, o si se quiere, un avanzado Tratado

1 Se debe recordar que el Tribunal Constitucional alemán definió a los Estados como "señores de los Tratados". 
internacional que pretende ser una Constitución y que, sin duda, llegará a ser un monumento o hito jurídico, aunque al final no se ratifique. Por eso, a nosotros nos interesará más la convergencia constitucional europea que ha dejado ya improntas indelebles en el constitucionalismo europeo.

\subsection{Vicisitudes de la ratificación del Tratado constitucional}

Puede datarse el origen del Proyecto del Tratado de Roma en el fracaso del Consejo Europeo de Niza de 26 de febrero de 2001, pues en la Declaración aneja 23 se propone el inicio de un debate institucional y social de los Estados miembros y Candidatos de cara a la refundación de Europa mediante una Constitución. Posteriormente en la Declaración de Laeken, tomando en consideración el éxito de la Primera Convención, que logró la aprobación de la Carta de los Derechos fundamentales, se propone una redacción híbrida en la que la labor de iniciativa le corresponda a una Convención que aúne a los Estados miembros y a los Estados Candidatos, a los delegados de las instituciones europeas y mediante la participación con audiencia de las organizaciones sociales y cuya labor sea revisada por el procedimiento intergubernamental tradicional de la CIG. La tarea de la Convención debía versar sobre un más nítido reparto de competencias, reducir la farragosidad de los tratados constitutivos, incrementar la transparencia y democracia y evaluar las posibilidades de una Constitución para Europa basada en una articulación federal.

La Convención estuvo integrada por 105 miembros, fue presidida por el ex-Presidente francés Giscard d'Estaing y con la vicepresidencia de los ex- Primeros Ministros Amato y Dehaene. El Texto del Proyecto de la Convención se elaboró desde el 27 de febrero de 2002 hasta el 13 de julio de 2003, fecha en la cual la Convención lo aprobó por consenso, prorrogándose sus trabajos hasta el 10 de julio².

2 Publicado inmediatamente como Proyecto de Tratado por el que se instituye una Constitución para Europa, Luxemburgo, Comunidades Europeas, 2003, pese a que por entonces no había concluido la CIG 2003-2004. DEL Río VILLAR, S., califica de revolucionaria la labor de la Convención en "Una sociedad civil, constituyente, para la nueva Europa", Unión Europea Aranzadi, Navarra, Thomson-Aranzadi, año XXXI, núm. 4, abril 2004, p. 27 y ss. Sin embargo, quisiéramos dejar constancia que hay pocas cosas originales, dado que el procedimiento de la Convención recuerda mucho los procedimientos constituyentes previstos en el sistema soviético. Para la visión del socialismo español, remitimos a BORRELL, J., CARNERO, C. y LóPEZ GARRIDO, D., Construyendo la Constitución europea. Crónica política de la Convención, Madrid, R. I. Elcano, 2003. 
El Proyecto de Tratado lo hizo suyo en una primera lectura el Consejo Europeo de Salónica del 20-21 de junio de $2003^{3}$ a los efectos de someterlo a la Conferencia intergubernamental, pero la labor de la CIG se prolongó de 2003 a 2004. El retraso en la aceptación fue debido a varios factores como la disparidad de la política exterior europea sobre la Guerra de Irak. El menosprecio de Alemania y Francia por el incumplimiento del pacto de Estabilidad y Crecimiento. Y, en fin, el veto implícito de España y de Polonia sobre el peso respectivo en la regla de la doble mayoría en la decisión del Consejo. La primera fase de la presidencia europea de Italia se caracterizó por la inutilidad o desinterés del Jefe de Gobierno Berlusconi y culminó con el fracaso del Consejo Europeo de diciembre de 2003 . Fue preciso esperar a la upresidencia irlandesa" en la que se apreció un momento de relajación de las relaciones inter-europeas debido, entre otras cosas, a que los Primeros Ministro de España y Polonia cesaron en sus cargos, y dado que el 1 de mayo de 2004 se produjo la ampliación de 15 a 25 Estados miembros de la Unión, de manera que el PTCR sería aprobado definitivamente en la cumbre o Consejo Europeo de Bruselas el 17-18 de junio de 2004 y firmado solemnemente por los Gobiernos de los 25 Estados miembros en Roma, el 29 de octubre de $2004^{4}$.

La ratificación que debería producirse antes del 1 de noviembre de 2006, o de un mes después, ya se sabía que sería un asunto difícil, puesto que si la mayoría de los Estados se conformaban con la ratificación parlamentaria, en cambio, casi una decena habían decidido acudir al referéndum popular. España, rompiendo con su tradición poco referendaria fue el primero en someterlo a referéndum el 20 de febrero de 2005 y el pueblo lo ratificó con una escasa participación, pero con una mayoría suficiente. Sin embargo, la gran conmoción se produjo con el referéndum francés de finales de mayo en el cual, con una alta participación, casi el $55 \%$ de los franceses votó no a la ratificación y una semana después casi dos tercios de los holandeses hizo lo mismo. Estados como el Reino Unido y Portugal que habían decidido acudir a los referendos, se volvieron atrás en la decisión y la situación de la construcción europea se hizo casi agónica dado que un tercio de los Estados fundadores había rechazado el Proyecto, por lo que sin entrar en las causas sí vino a demostrar que la pretendida transparencia democráti-

3 Las Conclusiones de la Presidencia del Consejo Europeo de Salónica pueden consultarse en la dirección http://www.europa.eu.int/council/off/conclu/index.htm.

4 Para estas precisiones nos hemos servido de AldeCoA LuZÁRRAGA, F., "Presentación" de Tratado por el que se establece una Constitución para Europa, Madrid, Biblioteca Nueva, 2004 (2. ${ }^{a}$ ed.). 
ca fue engañosa porque así lo probó la mayoría ciudadana. Se trató de poner remedio con el Consejo Europeo del 16 y 17 de mayo, pero puede decirse que fue peor el remedio que la enfermedad, pues el 16 al único acuerdo que se llegó fue el de posponer por un año más la fecha de la ratificación y el 17 de mayo terminó en un fracaso la reunión para el establecimiento de las perspectivas financieras que deberían mantenerse de 2007 a 2013. Posteriormente, ratificaron parlamentariamente el PCTR Chipre (el 30 de juio) Malta (el 6 de julio) y Luxemburgo lo sometió a referéndum el 10 de julio de 2005 y se ratificó razonablemente por el $56,52 \%$ de los luxemburgueses. A primeros de agosto de 2005, en que escribimos esto, el número de países que lo han ratificado han sido trece. Es verdad que el art. IV-443.4 establece que si 4/5 de los Estados miembros lo ratifican, la situación de los Estados que no lo han hecho se estudiará en un Consejo Europeo, pero la falta de Francia y Holanda ha generado un máximo europesimismo (o hasta una eurodepresión) sobre el futuro del Proyecto de Tratado Constitucional y parece que será necesario el estudio de otras vías ${ }^{5}$.

Europa ha pasado por varias crisis y hoy por hoy es una realidad; por eso, cabe esperar que esta última, pese a ser la más importante, habrá algún medio de superarla. De ahí que a continuación nos ocupemos de una cuestión vecina, que es una de esas realidades.

\section{LA CONVERGENCIA CONSTITUCIONAL EN LOS ESTADOS MIEMBROS DE LA UNIÓN EUROPEA}

Ante estos hechos, nos parece de la máxima oportunidad hacer un nuevo balance provisional de la convergencia constitucional en los Estados miembros de la Unión Europea, ya que se trata de una cuestión que no ha atraído especialmente el interés del constitucionalismo español. Tal particularidad de nuestro constitucionalismo es singular, dado que la homogeneización en las Constituciones de sus Estados miembros es la vertiente más relevante del proceso de integración del Derecho europeo (tanto del primario como del derivado, o secundario) en el Derecho interno nacional. Lo que sí ha apreciado nuestra doctrina - como, por ejemplo, el Profesor Rubio Llorente- es que en la Unión Europea estamos ya en una fase de un constitucionalismo integrado en lo que se refiere a las Constituciones de los Estados miembros de la

5 Para hacerse una idea del ánimo reinante en Europa en estos momentos puede verse VIDAL-Beneyto, J., "Qué hacer con Europa", El País, de 23 de julio de 2005, p. 10. 
Unión ${ }^{6}$, fenómeno que representa una aproximación de las Constituciones nacionales y que es la consecuencia de la integración de diversos Estados en una Entidad supranacional emergente, sin que eso signifique la desaparición de los Estados en que se fundamenta la Unión.

Comenzaremos disipando posibles equívocos y después seguirá una perspectiva general de los rasgos generales de la convergencia hasta la actualidad.

\subsection{Noción de la convergencia constitucional europea}

Por "convergencia constitucional» en sentido amplio se podría aludir a un doble proceso: de una parte, el proceso constituyente europeo, en estos momentos en crisis y, por otro lado, el fenómeno de la "convergencia constitucional» en sentido estricto o restringido, que consiste en la forma y la sustancia de la recepción en las Constituciones nacionales de los Estados miembros de las diversas etapas de la construcción europea y de su Derecho resultante. Desde esta perspectiva, la convergencia constitucional en sentido estricto, que es la que nos interesará a nosotros, constituye una parte del núcleo temático más amplio de "la relación entre la Constitución europea y las Constitucionales nacionales".

Hay que reconocer, empero, que esa necesidad de homogeneización constitucional todavía no se ha proclamado en ninguno de los Tratados Constitutivos, ni en el Derecho primario ni en el Derecho secundario europeo. De ahí que la cuestión que vamos a abordar se contemple unas veces como una manifestación de "convergencia constitucional», y otras -como hace el Profesor Cruz Villalón-como la expresión de una "armonización constitucional»" Personalmente, por razones semánticas, aunque no sólo por ellas ${ }^{8}$, preferimos la noción de

6 Rubio Llorente, F., "El constitucionalismo de los Estados integrados de Europa", Revista Española de Derecho Constitucional (REDC), Madrid, Centro de Estudios Políticos y Constitucionales, 48, 1996, p. 9 y ss.

7 Cruz Villalón, P., "Política constitucional de la Unión Europea: un marco de análisis", texto manuscrito de su ponencia al VIII Congreso de Sevilla de diciembre 2003 , p. 3 y ss. (en prensa).

8 Estimamos que, semánticamente, "convergencia» y "armonización" no son sinónimos, y tanto en el Derecho europeo como en el español: la armonización, como reconoce el propio CRUZ VILLALÓN, implica una imposición de la Unión sobre los Estados miembros y, en el Derecho autonómico español, del Estado sobre las Comunidades Autónomas (art. 150.3 de la Constitución española, en lo que sigue CE). 
"convergencia constitucional», entendiendo por tal el proceso paralelo a la convergencia económica y al procedimiento constituyente europeo que se desarrolla en los Estados miembros para adaptar su realidad constitucional a los avances de la integración europea. Esta convergencia, no proclamada institucionalmente - aunque resulta de una lógica jurídico-constitucional innegable, pese a que tolere excepcionesse está desarrollando, también lógicamente, en su mayor parte mediante reformas o revisiones constitucionales necesarias para la incorporación del Derecho primario e incluso del Derecho convencional o intergubernamental acordado entre los Estados de la Unión. Teniendo en cuenta la ampliación del espacio europeo de 15 a 25 Estados miembros en el pasado 1 de mayo de 2004, su examen sería un interesantísimo ejercicio de derecho constitucional comparado, que para el constitucionalismo tendría una relevancia semejante a la del proceso constituyente europeo propiamente dicho ${ }^{9}$. No obstante, hemos de reconocer que semejante examen desborda nuestras actuales posibilidades, por lo que en esta ocasión nos limitaremos al tratamiento de la cuestión en el ámbito de Europa Latina ${ }^{10}$. La reducción del marco de referencia a Portugal y España, por su mayor homogeneidad y porque ya llevan bastante tiempo formando parte de la Comunidad Europea, ofrece dos ventajas. Por una parte, permite obtener conclusiones más rotundas $y$,

9 Según la tipología de Pizzorusso, A., el trabajo sería una comparación jurídica, del tipo de derecho político y de acuerdo con una concepción europea del Derecho (Curso de Derecho comparado, Barcelona, Ariel, 1987, pp. 211 y ss., y 227 y ss.). En cambio, a tenor de la clasificación de PEgoraro, L. y RinelLA, A., el trabajo sería un ejercicio de Derecho Constitucional comparado, en su modalidad más elevada, al tratar de las reformas constitucionales (vid. "Concepto y evolución del Derecho Constitucional Comparado", en Nuevo Derecho Constitucional comparado [Dir. de López Garrido, D., Massó, M. F. y Pegoraro, L]. Valencia, Tirant lo Blanch, 2000, p. 36 y ss.).

10 De esta manera cumplimos parcialmente las recomendaciones de HÄBERLE, P., "Diritto costituzionale, unioni regionale fra stati e diritto universale dell'umanità: convergenze e divergenze" (en la página web de la Associazione Italiana dei Costituzionalisti -www.asociazionedeicostituzionalisti.it/-, núm. del 11 de mayo de 2004), autor que aprecia que "nell'America meridionale osserviamo gli sforzi di integrazione del "Mercosur", oppure il patto per i diritti umani degli stati andini andini (2002), il delinearsi di un "diritto costituzionale comune americano" che un giorno forse potrebbe convergere con il "diritto costituzionale comune europeo" (...) «il giurista svolge un compito peculiare: da giurista o costituzionalista anche "europeo" o "latinoamericano", da esperto di diritto costituzionale nazionale, da esperto di diritto comunitario e da esperto di diritto internazionale non può fare a meno di cooperare». Si bien HÄBERLE subraya entre las divergencias que "per la costituzione come cultura... il suo "paesaggio settentrionale, e meridionale» ci regalano un quadro di orientamento, e anche qualche coraggio". 
por otra, tolera en un estudio como este un tratamiento más pormenorizado del asunto, lo que nos habilita para la indagación histórica y contextual de esas reformas constitucionales y nos autoriza a examinar principios del constitucionalismo europeo que, si bien hoy no son generales, pudieran llegar a serlo (como, por ejemplo, las cláusulas de cobertura y los límites al proceso integrador, la descentralización territorial del poder ligada al principio de subsidiariedad, o la vertiente democrático-referendaria de la construcción europea, cuyo déficit ha sido muy criticado).

Hablando en términos generales de la convergencia constitucional de los Estados de la Unión Europea se puede adelantar que estamos ante una especie de convergencia constitucional tácita de los Estados miembros de la Comunidad Europea, que se manifiesta en un acusado activismo en la reforma constitucional, movimiento que empieza a percibirse avant la lettre con la firma en 1992 del Tratado de la Unión Europea (o de Maastricht, o abreviadamente TUE), razón por la que pretendemos ser exhaustivos únicamente desde esa fecha. Igualmente, desde un planteamiento inicial genérico se puede indicar que el elemento desencadenante suele ser la firma de los sucesivos Tratados de la construcción europea y que la forma de manifestación se produzca mediante reformas o revisiones de la Constitución (aunque ha habido notables excepciones). En consecuencia, en el tratamiento de la convergencia de los dos Estados miembros ibéricos el criterio de ordenación será la descripción de su sistema de reforma constitucional, la especificación cronológica de las manifestaciones de convergencia, con un apartado final de consideración de los referendos nacionales y la construcción europea.

\subsection{Rasgos generales de la convergencia constitucional en la actualidad}

Una vez anticipado el activismo reformista en pos de la convergencia constitucional, dejando a salvo la excepción española de las siete primeras Legislaturas, se puede afirmar que el fenómeno de aproximación constitucional hasta la fecha es amplio, pero limitado, formando un corpus que podríamos esquematizar en los siguientes rasgos o vectores de convergencia.

2.2.1. Entre los elementos determinantes de la homogeneidad constitucional tenemos que empezar destacando los requisitos o condiciones de adhesión de necesario cumplimiento por los Estados candidatos a integrarse definitivamente en la Unión Europea.

La primera de estas condiciones es que los Estados estén regidos por el principio de constitucionalidad o, como se dice en Alemania, por 
el principio del Estado constitucional (Verfassungsstaatlichkeit ${ }^{11}$ ), lo que implica en definitiva que la Unión Europea estará constituida por una comunidad de Estados constitucionales de Derecho. El precepto ya se formuló en el Tratado de Maastricht ${ }^{12}$, y en la versión consolidada de los Tratados se incluye en el art. 6.1, a cuyo tenor "La Unión se basa en los principios de libertad, democracia, respeto de los derechos humanos y de las libertades fundamentales y el Estado de Derecho, principios que son comunes a los Estados miembros". La mejor prueba de esta eficacia ex ante del principio de constitucionalidad es que ya se aplicó en nuestro marco de examen, pues Portugal y España no pudieron adherirse a las Comunidades europeas hasta que se desembarazaron de sus sistemas autoritarios a mitad de la década de los años setenta.

Por el momento, la única garantía de este principio es la contemplada en los dos primeros apartados del art.7 introducido ex novo por el Tratado de Amsterdam de 1997. En ambos preceptos se establece que:

«1. El Consejo, reunido en su composición de Jefes de Estado o de Gobierno, por unanimidad y a propuesta de un tercio de los Estados miembros o de la Comisión y previo dictamen conforme del Parlamento Europeo, podrá constatar la existencia de una violación grave y persistente por parte de un Estado miembro de principios contemplados en el apartado 1 del artículo 6 (...), tras invitar al Gobierno del Estado miembro de que se trate a que presente sus observaciones. 2. Cuando se haya efectuado dicha constatación, el Consejo podrá decidir, por mayoría cualificada, que se suspendan determinados derechos derivados de la aplicación del presente Tratado al Estado miembro de que se trate, incluidos los derechos de voto del representante del gobierno de dicho Estado miembro en el Consejo.... ${ }^{13}$.

11 HÄBERLE, P., El Estado constitucional, México, 2001, y WAHL, R., "Elemente der Verfassungsstaatlichkeit», Juristiche Schulung, 41, 11, 2001, p. 1.041 y ss.

12 Inicialmente lo fue en el art. F.1 del TUE. La numeración del texto es la que corresponde a la versión consolidada por los Tratados de Amsterdam de 2 de octubre de 1997 y de Niza de 26 de febrero de 2001. La edición que utilizamos es la del Código de la Unión Europea, Madrid, La Ley, 2003. En el proyecto de Tratado Constitucional, en la Parte I, Título I se incluye el Art. 2, que, bajo el epígrafe de «Valores de la Unión», establece que "La Unión se fundamenta en los valores de respeto a la dignidad humana, libertad, democracia, igualdad, Estado de Derecho y respeto a los derechos humanos. Estos valores son comunes a los Estados miembros en una sociedad caracterizada por el pluralismo, la tolerancia, la justicia, la solidaridad y la no discriminación".

${ }^{13}$ Se establece un precepto semejante en el Art. 58, del Título IX, de la Parte I del proyecto de TC. 
Igualmente son condición sine qua non o requisitos previos a la adhesión a la Unión Europea el respeto a los derechos fundamentales reconocidos en el Convenio de Roma y las tradiciones constitucionales comunes de los Estados miembros (que el Prof. Cruz Villalón califica como garantías adicionales del principio de constitucionalidad $^{14}$ ). Efectivamente, ya desde el Tratado de Maastricht de 1992 —art F.2, y apartado $2 .^{\circ}$ del art. $6 .^{\circ}$ de la versión consolidada de los Tratados después del de Amsterdam- se determinaba que: "La Unión respetará los derechos fundamentales tal y como se garantizan en el Convenio Europeo para la Protección de los Derechos Humanos y de las Libertades Fundamentales firmado en Roma el 4 de noviembre de 1950, y tal como resultan de las tradiciones constitucionales comunes a los Estados miembros como principios generales del Derecho comunitario" ${ }^{15}$. Consideramos que estos principios generales son auténticos requisitos previos a la integración, puesto que efectivamente el ingreso en el Consejo de Europa mediante la adhesión al Convenio Europeo de Roma ha sido considerado - por ejemplo, por el Prof. Molina del Pozo-como la antesala de la adhesión efectiva a la Unión Europea.

2.2.2. Antes de continuar con la descripción esencial de los elementos que integran ese corpus de la convergencia constitucional tenemos que detenernos en explicar las causas que hacen posibles las manifestaciones de divergencia constitucional, dado que, como se ha dicho, la convergencia tiene sus límites, ya que admite excepciones y no siempre se traduce en una reforma de la Constitución. Ello se debe a que desde el Tratado de Maastricht de 1992 la proto-Constitución o pre-Constitución europea ha proclamado que "La Unión respetará la

\footnotetext{
14 "Política constitucional...», cit., p. 9.

15 Ahora en la Parte I, Título II, Art. 7 del proyecto de TC, bajo el epígrafe «Derechos fundamentales" se incluye esta ambigua redacción: "La Unión reconoce los derechos, libertades y principios enunciados en la Carta de los Derechos Fundamentales que constituye la parte II de la Constitución. La Unión procurará adherirse al Convenio Europeo para la Protección de los Derechos Humanos y de las Libertades Fundamentales. Dicha adhesión no afectará a las competencias de la Unión que se definen en la Constitución. Los derechos fundamentales que garantiza el Convenio Europeo para la Protección de los Derechos Humanos y de las Libertades Fundamentales y los que son fruto de las tradiciones constitucionales comunes a los Estados miembros forman parte del Derecho de la Unión como principios generales". Respecto a la cuestión compartimos las conclusiones de SolOzÁBAL ECHAVARRía, J. J., "Constitución y orden constitucional en la Unión Europea», REP, núm. 119, 2003, p.79.
} 
identidad nacional de sus Estados miembros» ${ }^{16}$, lo cual significa el reconocimiento no sólo de que la Unión se fundamenta en sus Estados miembros, sino de que existe un ámbito constitucional de resisten$\mathrm{cia}^{17}$ formado en primer término por la soberanía constitucional que permanece en manos del Poder Constituyente y del Poder de Reforma constitucional de los Estados miembros ${ }^{18}$.

En consecuencia, lo precedente implica, en primer lugar, que sólo mediante el poder constituyente constituido extraordinario de reforma constitucional se podrá modificar - o suspender la aplicación, en su caso- el propio procedimiento de reforma; en segundo, que, en virtud del principio de derivación constitucional que rige el sistema de fuentes de un Estado constitucional de Derecho, por medio de la revisión constitucional se podrá modificar ese sistema de fuentes y, por consiguiente, definir cómo se integra en el Derecho nacional el acervo normativo europeo; en tercer lugar, el poder de reforma delimita el ámbito constitucional de resistencia optando por los contenidos de ese acervo europeo que debe constitucionalizarse; $y$, en fin, ese poder también puede tolerar mutaciones constitucionales o inconstitucionales. $Y$ las dos últimas razones explican la anomalía española con respecto a la convergencia constitucional, pues se ha utilizado generalmente la Ley Orgánica como medio de adopción del contenido sustancial de la convergencia.

2.2.3. Con la digresión que antecede como justificación previa de las posibles divergencias, se explica que ordenemos el resto del corpus de la convergencia constitucional en función de las vertientes orgánica (o subjetiva), formal y material o del contenido de la reforma constitucional (o sustantiva).

\footnotetext{
${ }^{16}$ Arts. F.1 del TUE y 6.3, de acuerdo con la versión consolidada por los Tratados de Amsterdam y de Niza. En el apartado $1 .^{\circ}$, del art. 5, del Título I, de la Parte I del proyecto de TC se amplia la redacción a lo siguiente: "La Unión respetará la identidad nacional de los Estados miembros, inherente a las estructuras fundamentales políticas y constitucionales de éstos, también en lo que respecta a la autonomía local y regional. Respetará las funciones esenciales del Estado, en particular las que tienen por objeto garantizar su integridad territorial, mantener el orden público y salvaguardar la seguridad interior".

17 O, como indica CRUZ VILLALÓN, P., es un factor de asimetría constitucional en los Estados miembros ("Política constitucional...", cit., p. 7 y ss.).

18 HÄBERLE, P., identifica como primer elemento de divergencia que "lo Stato costituzionale resta un elemento irrinunciabile perché è dotato di una propria identità culturale. Si trata di una 'casa patria' per tutti i suoi cittadini, anche se all'interno la casa è 'localizzabile' in strutture federali o regionali» ("Diritto costituzionale...", loc. cit.).
} 
Dimensión orgánica. El parlamentarismo es la forma de gobierno europea, por lo que no tiene nada de particular que sea regla general la intervención de las Cámaras parlamentarias en la reforma constitucional, aunque también es normal que se exijan mayorías absolutas y hasta cualificadas.

En cambio, todavía hay profundas divergencias con respecto a la democracia directa o referendaria, pues únicamente en algunos Estados miembros de la Unión se exige la ratificación de la labor revisora parlamentaria por el Pueblo o el Cuerpo electoral mediante el referéndum que, en la mayoría de los casos, es facultativa (u opcional), aunque hay casos en que el referéndum de ratificación es preceptivo (u obligatorio). Por fortuna en los referendos sigue rigiendo la regla de la mayoría simple o relativa, pues es innegable que cuanto más rígida sea una Constitución más difícil le resultará la adaptación a las sucesivas fases de aprobación de los Tratados relativos a la construcción europea ${ }^{19}$.

En este apartado de visión general acerca de la homogeneización constitucional entre las Constituciones de la Europa Latina se puede anticipar que el elemento desencadenante de la mayor parte de las reformas constitucionales es la celebración de Tratados internacionales, y especialmente de los sucesivos Tratados de la construcción europea, por lo que se aprecia que cada vez son más precisas las reformas constitucionales, pues se procura asegurar la compatibilidad entre las normas convencionales adoptadas y las normas constitucionales. De ahí que, en cuanto a la dimensión orgánica de la reforma constitucional, tiene interés apreciar si pueden intervenir otros órganos, además del Cuerpo representativo y del Cuerpo electoral. Y, efectivamente, en la mayoría de los casos se habilitan procedimientos que permiten que se pronuncie el Tribunal Constitucional antes de la ratificación del Tratado internacional acerca de la constitucionalidad de ese Tratado ${ }^{20}$.

19 A pesar de que se trata de un aspecto esencial desde un punto de vista democrático y evidentemente sustancial para las revisiones que coadyuvan a la construcción europea, desde la perspectiva clásica de la reforma constitucional la existencia de un referéndum de ratificación se debe considerar como parte de la dimensión orgánica con respecto a la revisión. Decimos que sobre esta cuestión hay profunda divergencia, pues, si hay homogeneidad al respecto entre Francia, Italia y España —que en ocasiones acudieron o acudirán al referéndum constitucional para las decisiones sobre Europa-, en cambio, en Alemania y Portugal parece que se siguen aferrando a la desconfianza clásica hacia la democracia directa como en los tiempos de Kaustky.

20 Así se ha producido con importantes Sentencias de los Tribunales Constitucionales de Alemania, la Declaración del Tribunal Constitucional español, de la Corte Constitucional de Italia y con Decisiones del Conseil Constitutionnel de Francia. 
Empezando con la dimensión formal-instrumental del acto normativo de reforma de los procedimientos de revisión constitucional, hay una manifiesta convergencia, en la medida en que la gran mayoría de las reformas constitucionales se practican mediante una Ley Constitucional, una fuente o acto normativo ad hoc y común, que tiene la fuerza activa y la fuerza pasiva de las normas constitucionales ${ }^{21}$.

Siguiendo con la perspectiva sistemático-formal de las reformas, se empieza a detectar, como incipiente factor de convergencia, la tendencia -observada en otro grupo de Estados miembros de la Unión- a sistematizar la totalidad o la mayor parte de las materias constitucionales relacionadas con las Comunidades Europeas en un Título, o incluso en toda una Sección constitucional, o en un extenso artículo ${ }^{22}$. Estimamos que esta modalidad de sistematización formal terminará imponiéndose de modo general, pues es la que parece más recomendable ante la envergadura de la materia constitucional relacionada con la integración europea.

Pasando a los elementos de convergencia con relación al contenido, sin ningún ánimo de exhaustividad, se pueden enumerar bastantes.

Interesa, en primer término, si se ha constitucionalizado el proceso de la progresiva integración europea y se han establecido cláusulas de cobertura o límites de intangibilidad ante ese proceso. La constitucionalización de la integración europea es importante porque, de ese modo, el Estado que la haya realizado dispone de un fundamento o título en la Constitución para la convergencia constitucional, o, si se quiere, de una cláusula de cobertura interna. Las cláusulas de cobertura se orientan hacia la progresiva integración europea de su Derecho y, por consiguiente, vendrán a ser condiciones o límites al proceso de integración, o factores internos de un ámbito de resistencia total, o elementos de asimetría estatal interna ${ }^{23}$.

21 Esta regla se cumple, por ejemplo, en Francia, Alemania e Italia. Italia constituye una originalidad, puesto que allí la Ley Constitucional no se utiliza solamente para la revisión expresa, formal o instrumental de las normas constitucionales, sino que también se emplea para derogarlas parcialmente, o condicionar su aplicación, e incluso privarlas de eficacia.

${ }^{22}$ Es paradigmático del primer supuesto el «Título XIV. De las Comunidades Europeas y de la Unión Europea», de la Constitución francesa; sirva de ejemplo del segundo lo sucedido con la Ley Constitucional Federal de Austria, en su "Parte Primera. Disposiciones generales de la Unión Europea" con la nueva "Sección. Apartado B) De la Unión Europea»; e ilustra el tercero el art. 23 o "Artículo de Europa" de la Ley Fundamental de Bonn.

${ }^{23}$ Cuentan con diversas cláusulas de cobertura los textos constitucionales de 
Es apreciable la convergencia en el reconocimiento del importante principio de subsidiariedad, principio que en el Tratado de Maastricht se incluye entre los límites de las atribuciones de la Comunidad Europea y que, sin embargo, en el Tratado de Amsterdam se incorpora a los objetivos de la Unión y, por tanto, se convierte también en principio de distribución territorial y vertical del poder político o administrativo en los Estados miembros ${ }^{24}$. En consecuencia, el Derecho primario europeo incentiva sustantivamente la descentralización territorial del poder político y de la gestión administrativa de los recursos más cercana a los ciudadanos y propugna una regionalización que permita conseguir un desarrollo sostenible y equilibrado ${ }^{25}$.

Otro elemento de convergencia inevitable es la democracia paritaria de sexos (o de géneros, como se suele decir en España), es decir la igualdad de oportunidades de hombres y mujeres en el derecho de sufragio pasivo, lo cual únicamente parece realizable en las fórmulas electorales de representación proporcional de los votantes ${ }^{26}$.

Paradójicamente para unos, y lógicamente para otros, el proceso precedente se acompaña con el vector convergente de la constitucionalización del idioma oficial de cada Estado miembro. Decimos que es lógico, dado que los idiomas oficiales de los Estados miembros también lo son de la Unión Europea.

Austria, Francia, Alemania y Portugal; Italia todavía no las ha establecido, aunque sí las ha definido su Corte Costituzionale.

${ }_{24}$ Art. G.3.B del TUE, y art. 2 in fine del Tratado de Amsterdam.; en el proyecto de TC ha pasado al Título III, dedicado a las competencias de la Unión, estableciéndose en el art. 9.1 entre los "Principios fundamentales" que: "La delimitación de las competencias de la Unión se rige por el principio de atribución. El ejercicio de las competencias de la Unión se rige por los principios de subsidiariedad y proporcionalidad". Como ha advertido RESCIGNo, G.U., el principio de subsidiariedad, tras su incorporación en el articulado de la Constitución italiana, puede atentar contra el equilibrio de la solidaridad entre las Regiones, por lo que cabe esperar que las reformas constitucionales subsiguientes se rijan por el principio de proporcionalidad (Corso di Diritto Pubblico, Bolonia, Zanichelli, 2001-2002, 6. ${ }^{\text {a }}$ ed., p. 569).

${ }_{25}$ Alemania y Austria, al estar ya descentralizadas políticamente en Länder, han regulado constitucionalmente la participación de estas Entidades político-territoriales en el proceso europeo de integración y, recientemente, también lo ha hecho Italia.

26 Así, recientemente, han reformado sus Constituciones Francia, mediante la Ley Constitucional 99-569 del 8 de julio de 1999, e Italia, mediante la Ley Constitucional núm. 1 de 2003, de 20 de febrero, de modificación del art. 51 de su Constitución. 
Con el Tratado de Maastricht se reconoció el estatus de ciudadano de la Unión Europea, al que se asociaron algunos derechos políticos (de escasa significación) y diplomáticos ${ }^{27}$.

A pesar de no estar impuesto de un modo explícito en el Derecho europeo primario, con mucha frecuencia los sistemas parlamentarios europeos prevén la participación de los Parlamentos nacionales en la construcción europea ${ }^{28}$. E incluso prevén la intervención parlamentaria en los nombramientos de las autoridades y altos funcionarios de la Comunidad Europea. Asimismo, se puede constitucionalizar la fórmula electoral de los representantes nacionales en el Parlamento Europeo ${ }^{29}$.

Igualmente, con el Tratado de Maastricht se alcanza la etapa o fase de la Unión Económica y Monetaria, así como la creación del euro y del Banco Central Europeo, lo que puede repercutir en las Constituciones para la reordenación de las funciones de los Bancos Centrales de los Estados miembros, o bien en la celebración de referendos para la admisión del euro (como el que estaba previsto que se celebre próximamente en Inglaterra y que sí se celebró en Francia).

También se detecta la convergencia - constitucional o subconstitucional- de erradicación de la pena de muerte como un hito irrenunciable en la civilización y, así, en la Declaración n. ${ }^{\circ} 1$ del Tratado de Amsterdam se interpreta la abolición de la pena de muerte en Europa conforme al Protocolo n. ${ }^{\circ} 6$ del Convenio Europeo de Roma para la protección de los derechos humanos y de las libertades fundamentales firmado el 28 de abril de $1983^{30}$. Igualmente es importante en el orden penal el Convenio de aplicación del Acuerdo de Schengen, relativo a la supresión gradual de los controles en las fronteras comunes, de 19 de junio de 1990, Convenio que no representa un estricto Derecho primario o secundario europeo, sino meramente un Derecho convencional para los Estados miembros adheridos ${ }^{31}$. A partir del Convenio Europeo para

${ }_{27}$ En el TUE se recogía este estatus en los arts. 8, $8 B, 8 C, 8 D$ y $8 E$; en la última versión consolidada de los tratados se incluyen en la Parte II, Segunda Parte (arts. 17-22), y en el proyecto de TC se le dedica el art. 8. ${ }^{\circ}$ del Título II de la Parte I.

${ }_{28}$ Como, por ejemplo, en la Ley Fundamental de Bonn, en la Constitución francesa de la V. ${ }^{a}$ República y en la Constitución portuguesa, así como en la Ley Constitucional Federal austriaca, texto este último que también prevé la participación del Parlamento en los nombramientos de nacionales para las Instituciones europeas.

29 Sin ir más lejos, así se hizo en la Ley Constitucional Federal austriaca.

30 Como se sabe, este ha sido uno de los argumentos principales para retrasar la candidatura de Turquía en la adhesión a la Unión Europea.

31 La aplicación del acuerdo motivó en Francia la reforma constitucional mediante Ley Constitucional 93-1.256, de 25 de noviembre de 1993. 
la represión del terrorismo, de 27 de enero de 1977, desarrollado por la Decisión 2002/187/JAl del Consejo, de 28 de febrero de 2002, por la que se crea Eurojust para reforzar la lucha contra las formas graves de delincuencia, se genera el agravamiento de las penas y la supresión de limitaciones jurídicas en los supuestos de delitos de terrorismo y de tráfico de personas o de estupefacientes. Para finalizar con el ámbito criminal, es importante la Decisión marco del Consejo Europeo de Tampere, de 13 de junio de 2002, relativa a la orden de detención y captura europea y a los procedimientos de entrega entre Estados miembros, conocida también como la "euro-orden", que en determinados supuestos suprime los procedimientos de extradición entre Estados miembros ${ }^{32}$.

\section{REFORMAS Y CONVERGENCIA CONSTITUCIONAL EUROPEA EN PORTUGAL}

La Constitución portuguesa de 2 de abril de 1976 surgió de una Asamblea Constituyente elegida democráticamente el 25 de abril de $1975^{33}$, y en el fragor y fervor de la "revolución de los claveles", conducida por el Movimiento de las Fuerzas Armadas, con el objetivo de romper con el autoritarismo precedente e iniciar la transición hacia el socialismo. Este Movimiento terminó cediendo el paso a las urnas y, en consecuencia, se hicieron necesarias muchas rectificaciones por medio de las reformas constitucionales ${ }^{34}$. La adhesión de España y de Portugal tuvo lugar al mismo tiempo, de modo que en los dos Estados la integración del Derecho europeo se produjo en la misma fecha de 1 de enero de 1986, pero en Portugal comenzaron con revisiones constitucionales previas a la Adhesión.

32 Francia tuvo que modificar igualmente su Constitución por medio de la LC 2003-267, de 26 de marzo de 2003 y Alemania el art. 16 de la Ley Fundamental. Como se sabe, en julio de 2005 se ha suscitado un grave conflicto porque el Tribunal Constitucional Federal alemán negó la aplicación de la euro-orden a un terrorista buscado por España al considerar que la legislación de desarrollo de la Ley Fundamental no era plenamente garantista. Produce un cierto rubor las recriminaciones y consejos españoles a Alemania, cuando España, que si cuenta con la legislación de desarrollo, en cambio, no ha constitucionalizado el contenido de la Decisión marco de Tampere (Cf. El País, del 19 de julio de 2005, p. 2 y del 26 de julio de 2005, p. 25).

33 Al respecto vid. Gaspar, J. y Vitorino, N., As eleições de 25 de abril, Lisboa, Horizonte, 1976, y GoNZÁLEZ HERNÁNDEZ, J. C., "El régimen político portugués", en $R e$ gímenes políticos actuales (Coord. de J. Ferrando), Madrid, Tecnos, 1985, p. 445 y ss.

34 Son opiniones autorizadas al respecto las de Gomes CANOTILHO, J. J. y MoREIRA, V., Constituição da República portuguesa anotada, Coimbra, Coimbra ed., 1984,

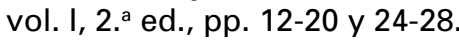


Para mantener el mismo orden sistemático en el ámbito ibérico seguiremos el del segundo apartado de este trabajo, por eso, nos ocuparemos primero de las condiciones previas a la adhesión, y a continuación recordaremos las posibles causas de las divergencias.

Ciertamente que en Portugal se dan las condiciones de integración pues, como Estado constitucional de Derecho que es, se rige por el principio de constitucionalidad y, para probarlo, basta con retener que su Constitución es rígida y el control de la constitucionalidad de las leyes y de otros actos jurídicos se encomienda a su Tribunal con un completo sistema de procedimientos para incoar su intervención.

Igualmente, en Portugal se dan las causas para una posible divergencia o un ámbito de resistencia constitucional a la integración, pues podremos comprobar cómo ha adaptado su sistema de fuentes a la integración del Derecho europeo, ha podido optar por constitucionalizar o adoptar mediante ley el acervo europeo, y ha establecido su propio sistema de cláusulas de cobertura.

\subsection{Los procedimientos de reforma constitucional portugueses}

Manteniendo la sistemática anterior, desarrollaremos este apartado atendiendo a las vertientes orgánica, formal y material (o del contenido) del sistema de reforma de la Constitución portuguesa de 1976 (en adelante, CRP).

Están previstas dos posibilidades de reforma constitucional, la que podemos llamar ordinaria y la extraordinaria, que se regulan en los arts. constitucionales 284 a 289. La reforma ordinaria, y más habitual, está reglada en el art. 284.1 de la Constitución, y se realiza cada cinco años con la aprobación de los dos tercios de los diputados de la Asamblea de la República. La revisión extraordinaria procede cuando se pretenda efectuar antes de que transcurran cinco años desde la anterior, y cuando lo soliciten los cuatro quintos de los diputados de la Asamblea de la República (art. 284.2), lo cual exige un consenso de los más elevados del derecho comparado, aunque últimamente, las exigencias de la convergencia constitucional están exigiendo acudir con más frecuencia al procedimiento extraordinario de revisión. En ninguno de los dos procedimientos cabe el veto o la devolución del proyecto por el Presidente de la República, que está obligado y limitado a promulgarla, si bien podrá retrasarla (art. 286.3 de la Constitución) ${ }^{35}$.

35 En el art. 288 de la CRP se incluye un original catálogo de límites materiales a la revisión: "As leis de revisão constitucional terão de respeitar: a) A independência 
En cuanto a la dimensión orgánica de la reforma constitucional, dado que la República lusitana hermana sigue siendo una modalidad de gobierno parlamentario, ha encomendado la revisión exclusivamente a su Asamblea; en definitiva, en terminología del Prof. Mortati ${ }^{36}$, el sistema de reforma de la Constitución portuguesa es muy "aristocrático", y más que el español, pues no sólo no permite su ratificación mediante el referéndum constitucional, sino que, según parece, prohíbe los referendos acerca de esa cuestión, de tal suerte que la revisión la efectúa únicamente la Asamblea (art. 115.4 $\mathrm{CRP}^{37}$ ). No obstante, dado que la ratificación de los Tratados se produce, como en la mayoría de los Estados miembros, mediante ley de la Asamblea de la República, es concebible la posibilidad de que se verifique su compatibilidad con la Constitución de 1976, por el Tribunal Constitucional y según parece la ratificación popular del Tratado constitucional de Roma ${ }^{38}$.

En lo que concierne a la dimensión formal-instrumental de la revisión, en Portugal se practica, como en la mayoría de los Estados miembros de la Unión Europea, mediante una forma de acto normativo ad

nacional e a unidade do Estado;b) A forma republicana de governo; c) A separação das Igrejas do Estado; d) Os direitos, liberdades e garantias dos cidadãos; e) Os direitos dos trabalhadores, das comissões de trabalhadores e das associações sindicais; f) A coexistência do sector público, do sector privado e do sector cooperativo e social de propriedade dos meios de produção; g) A existência de planos económicos no âmbito de uma economia mista; h) O sufrágio universal, directo, secreto e periódico na designação dos titulares electivos dos órgãos de soberania, das regiões autónomas e do poder local, bem como o sistema de representação proporcional; i) O pluralismo de expressão e organização política, incluindo partidos políticos, e o direito de oposição democrática; j) A separação e a interdependência dos órgãos de soberania; I) A fiscalização da constitucionalidade por acção ou por omissão de normas jurídicas; m) A independência dos tribunais; n) A autonomia das autarquias locais; o) A autonomia político-administrativa dos arquipélagos dos Açores e da Madeira». En cuanto a los aspectos teóricos de los límites materiales a la reforma constitucional vid. Gomes CANotilho, J. J., Direito Constitucional e Teoria da Constituição, Coimbra, Almedina, 2002, p. 1.053 y ss.

${ }_{36}$ S.v. "Costituzione dello Stato. b) Dottrine generali e Costituzione della Repubblica italiana», en Enciclopedia del Diritto, t. XI, p. 188.

37 En demostración del inicial recelo político portugués ante los referendos nacionales veánse MiRANDA, J., Manual de Direito Constitucional, Coimbra, Coimbra

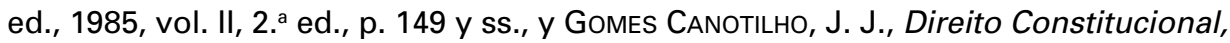
Coimbra, Almedina, 1986, 4. ${ }^{\text {a }}$ ed., p. 746.

38 En noviembre de 2004 la Asamblea de la República exigió la celebración de un referéndum, pero la cuestión planteaba en realidad tres preguntas, por lo cual el Tribunal Constitucional -como ya hizo para la ratificación del Tratado de Amsterdamha juzgado improcedente este tipo de consulta, por lo que se estima que dicho referéndum se aplazará. 
hoc: la Ley Constitucional. En cuanto a la vertiente sistemático-formal, tendremos ocasión de comprobar que la regulación relativa a la integración europea es abundante, pero dispersa a lo largo de todo el articulado del texto constitucional, de manera que no se ha incorporado toda ella o su mayor parte en un apartado específico de la CRP. Esa misma abundancia ya prueba que en la Constitución portuguesa sí se han apreciado las consecuencias jurídico-constitucionales de la construcción europea.

\subsection{La convergencia europea en las reformas constitucionales de Portugal}

Desde la aprobación de la Constitución de 1976 en Portugal se han producido seis revisiones constitucionales. Las dos primeras, de 1982 y de 1989, despojaron a la Constitución de las aristas más agudamente revolucionarias de su inicial formulación y flexibilizaron la economía ${ }^{39}$.

La Primera Revisión, de 1982, en lo que nos interesa a nosotros, destaca por la supresión de la Comisión Constitucional y del Consejo de la Revolución, que eran los órganos que utilizaba el Movimiento de las Fuerzas Armadas para condicionar el proceso político, siendo sustituida la Comisión por un auténtico Tribunal Constitucional ${ }^{40}$. Y, además, antes de la adhesión formal a las Comunidades Europeas, en el art. 112.9 CRP ya se previó la reordenación del sistema de fuentes para la recepción del Derecho europeo secundario o derivado ${ }^{41}$.

La Segunda Revisión, de 1989, siguió liberalizando la economía, y es reseñable porque abolió la irreversibilidad de las nacionalizaciones efectuadas tras la Revolución del 25 de abril de 1974 y porque introdujo con mucha cautela el referéndum de carácter nacional ${ }^{42}$. No obstan-

39 La edición más actualizada de la Constitución portuguesa que hemos podido utilizar es la de http://www.parlamento.pt, que incluye una versión en español.

40 Para una síntesis de la Primera de las revisiones constitucionales vid. MIRANDA, J., Manual..., cit., vol. I, 3. ${ }^{\text {a }}$ ed., p. 354 y ss., o "Introduction» a la Constitución de la República de Portugal, en Recueil des Constitutions européennes (ed. de F. Delpérée et al.), Bruselas, Bruylant, 1994, pp. 696-698; o Gomes CANotilho, J. J. y Moreira, V., Constituição..., cit., vol. I, pp. 20-25. Acerca de este Tribunal constitucional véanse CARdoso DA CostA, J. M. M., A Jurisdição Constitucional em Portugal, Coimbra, Almedina, 1992, 2. a ed., y FAVOREU, L., Los Tribunales Constitucionales, Barcelona, Ariel, 1997, pp. 126-131.

41 Miranda, J., "Portugal...", cit., p. 392.

42 El resumen de la Segunda Reforma se puede consultar en MiRANDA, J., "Introduction...", cit., pp. 698-701, y en CARDOSO DA COSTA, J. M. M., "A evolução cons- 
te, lo que nos importa es señalar que con esta reforma se retocó el art. 8.3 sobre la recepción del Derecho europeo y ya se introdujo una regulación relativa al Parlamento Europeo ${ }^{43}$.

De la Tercera Revisión, de 1992, son bastantes más los elementos novedosos de convergencia que nos interesan, pues se trataba de hacer posible la ratificación del Tratado de Maastricht, que, como se ha dicho, es el desencadenante del proceso de convergencia constitucional europea.

Con esta revisión se introduce un precepto genérico mediante el que se procura cobertura constitucional a la participación del Estado en la construcción europea y se incluyen límites o condiciones a esa construcción, cuales son los principios de reciprocidad, la realización de la cohesión económica y social, y el respeto al principio de subsidiariedad $^{44}$. EI TUE se significa por el reconocimiento de la "ciudadanía de la Unión Europea" y una serie de derechos conexos y, entre ellos, el derecho de sufragio activo y pasivo en las elecciones municipales a los europeos residentes en otros Estados miembros, por lo que con esta Reforma se introdujo el precepto del art. 15.4 de la CRP. La previsión de la participación de la Asamblea en la construcción europea se reguló en sus arts. $161, \mathrm{n} ; 163, \mathrm{f} ; 164, \mathrm{p}$ y 197.1 , i de la vigente Constitución ${ }^{45}$. Igualmente se disciplinó la colaboración de las Regiones autónomas (párrafos $v$ y $x$ del art. 227.1) ${ }^{46}$. Por último, con la reforma de 1992 se incorporaron preceptos constitucionales que permiten la adaptación del

titucional no quadro da Constituição da República de 1976», Boletim da Faculdade de Dereito de Coimbra (B.F.D.), 70, 1994, pp. 401-403.

43 Sin embargo, en la cuarta revisión constitucional de 1997 se suprimió la antigua regulación de las elecciones al Parlamento Europeo, manteniendo unas menciones a esas elecciones en el art. 119.1, i) y 133, b) CPR.

${ }_{44}$ No incluimos entre las condiciones determinadas frente a la construcción europea el principio de reciprocidad, por tratarse de una norma intrínsecamente jurídico-internacional y, por tanto, metaconstitucional. El criterio de reciprocidad se exige en el art. 7.6 de la Constitución portuguesa y también se introdujo en la reforma constitucional francesa de 1992 en el art. 88-2.

45 En Portugal la participación de la Asamblea de la República en materia europea se introdujo por medio de la tercera reforma de 1992 al adicionar los párrafos $163, f$ y 197.1,i; por último, también con relación a la participación en materia europea del Parlamento, en la citada cuarta revisión de 1997 se introdujeron, asimismo, un nuevo párrafo $n$ al art. 161, de acuerdo con la nueva numeración, y un nuevo párrafo $p$ al art. 164 .

46 Portugal esperó hasta la cuarta revisión constitucional de 1997 para introducir los párrafos $v$ y $x$ del art. 227.1 por los que se admite cierta participación de las Regiones en la unificación europea. 
Banco de Portugal a la nueva fase de la Unión Económica y Monetaria, por lo que fue modificado el art. $102 \mathrm{CRP}^{47}$.

Para dar una visión general de la Cuarta Revisión constitucional, de 1997, bastante amplia y enjundiosa, empezamos señalando que emprende la adaptación de la Constitución al Tratado de Amsterdam admitiendo la capacidad electoral de los ciudadanos extranjeros, así como la posibilidad de creación de distritos electorales uninominales y el derecho de iniciativa legislativa de los ciudadanos, y reforzando los poderes legislativos de la Asamblea, que compartía con el Presidente de la República y con órganos de origen revolucionario; además, entre las atribuciones de la Asamblea se prevé la participación en la designación de los miembros portugueses en la organización Comunitaria (art. 164. $p$ ) y las precisiones aludidas anteriormente con respecto a las elecciones al Parlamento europeo ${ }^{48}$.

La Quinta Revisión constitucional ya fue aprobada por la Ley Constitucional $n .^{\circ} 1 / 2001$, de 12 de diciembre, y constituye la primera manifestación de la revisión de carácter extraordinario. Tal vez por el alto grado de consenso parlamentario exigido se introducen menos reformas, lo que también viene a demostrar que Portugal cuenta con una Constitución más asentada. En concreto, la revisión de 2001 tuvo por objeto el reconocimiento de la jurisdicción del Tribunal Penal Internacional. Sin embargo, a las condiciones de reciprocidad ${ }^{49}$, de la realización de la cohesión social y económica y del principio de subsidiariedad, se añade como nueva cláusula de cobertura la existencia de un espacio de libertad, seguridad y justicia, y se acuerda el ejercicio en común o en cooperación de los poderes necesarios para la construcción de la unidad europea. Se proclama como lengua oficial del Estado el portugués. Igualmente, se rechaza la extradición por delitos políticos o por aquellos a los que en el Estado que la solicita corresponda la pena

47 Vid. Cardoso da Costa, J. M. M., "A evolução...", cit., pp. 403-405.

48 Se puede examinar esta Cuarta revisión en las colaboraciones al respecto de V. Moreira, M. B. Urbano, C. Sarmiento e Castro, C. Sampaio Ventura y P. Veiga, en las pp. 405-555, del núm. 74 de 1988 del BFD, así como, singularmente, las reflexiones de Gomes CANotilho, J. J., acerca de su significado en Direito Constitucional e Teoría..., cit., pp. 211-214.

49 A los extranjeros de lengua portuguesa con residencia permanente en Portugal (os retornados) también se les reconocen derechos en términos de reciprocidad —derechos que no son conferidos a los demás extranjeros-; en cambio, sólo los portugueses podrán acceder a la Presidencia de la República, a la Presidencia de la Asamblea, al cargo de Primer Ministro, a las magistraturas en el Tribunal Supremo, al servicio en la Fuerzas Armadas y a la Carrera Diplomática. 
de muerte o lesión irreversible de la integridad física. En fin, se restringe la inviolabilidad del domicilio en los casos de delitos de criminalidad especialmente violenta u organizada, incluyendo el terrorismo y el tráfico de personas, armas o estupefacientes ${ }^{50}$.

La sexta revisión, fue aprobada por la Asamblea el 25 de abril de 2005, publicado el Decreto Constitucional núm. 1/X de 8 de junio, y promulgada por la Ley Constitucional 1/2004 (si bien la fecha oficial es la simbólica del 25 de abril ${ }^{51}$, de nuevo con carácter extraordinario y por una mayoría superior a los $4 / 5$. La mayor parte de la reforma se dedica a la regionalización política del Continente portugués, asimilándolo más al modelo de las Comunidades Autónomas que al modelo francés de descentralización de signo administrativista.

En lo que se refiere a la construcción europea se incorporan como mucho estilo cláusulas de cobertura con respecto al art. I-6 del Tratado constitucional. Efectivamente en el ar. 2 del proyecto de reforma constitucional en el que se manifiesta:

«Portugal, en condiciones de reciprocidad, respetando los principios fundamentales del Estado de derecho democrático y el principio de subsidiariedad y en perspectiva a la realización de la cohesión económica, social y terrirorial, de un espacio de libertad, seguridad y justicia y la definición y ejecución de una política externa, de seguridad y de defensa común, puede acordar el ejercicio, en común, en cooperación o por las instituciones de la Unión, de los poderes necesarios para la construcción y profundización de la unión europea».

Y en el artículo octavo de la nueva Constitución se añadirá un apartado $4 .^{\circ}$, con la siguiente redacción: "Las disposiciones de los tratados que rigen a la Unión Europea y las nomas emanadas de sus institucionesns, en el ejercicio de las respectivas competencias, son aplicables en elorden interno, en los términos definidos por el Derecho de La Unión, con respeto por los principios fundamentales del Estado de derecho democrático.»

Además en el párrafo $x$ ) del apartado $1 .^{\circ}$ del art. 227 se prevé el doble sentido de la participación regional en la construcción europea: «Participar en el proceso de la construcción europea, mediante la representación de las respectivas Asambleas regionales y en las delegaciones comprometidas en procesos de decisión de la Unión Europea, cuando estén en juego materias que les indiquen como tansponer actos jurídicos de la Unión en los términos del articulo 112" Artículo que en su apartado 7 determina: "La transposición de los actos jurídicos de la Unión Eurpea

\footnotetext{
50 Véase loc. cit. de internet.

51 En el lugar citado de internet está la versión que utilizamos y advertimos que ya cuenta con la versión en español.
} 
para el ordenamiento jurídico, según sus términos adoptán la forma de ley, de decreto ley y en los términos de lo dispuesto en el número 4, el de decreto legislativo regional".

Y, por fin, también se incorpora un precepto para constitucionalizar la euroorden.

En cuanto a las demás reformas importantes evaluamos así el dedicado a la Regulación de la Comunicación Social y a la constitucionalización de la Alta Autoridad de la República para la Comunicación.

La regionalización total del territorio estatal desde arriba, asociada a satisfacer las exigencias de la subsidariedad, no se había alcanzado por un fracaso referendario. Podemos radiofotografiar el regionalismo del Continente europeo occidental indicando que la descentralización más profunda políticamente es la española, el menos y por lo tanto el más administrativo el francés, $y$, el italiano lo debemos calificar como mixto; pues bien, el regionalismo portugés que pretende crear la sexta reforma es un regionalismo a medio camino entre el español y el italiano. Todas las Regiones contarán con un Gobierno y una Asamblea regional que emanan un acto normativo típico y difrenciado: el Decreto Legislativo regional, el cual podrá versar en una serie de materias que se le atribuyen con el carácter de exclusivas, por lo que podrám adoptar un gobierno propio sobre ellas. Los Estatutos político-administrativos, como los españoles, no podrán ser adoptados unilateralamente por las Regiones; en cambio, como en Italia, es la disolución anticipada de la Asamblea la que produce la dimisión de todo el Gobierno.

\subsection{Los referendos en Portugal}

Pensamos que hay que comentar aquí lo sucedido con el referéndum constitucional de carácter nacional reconocido en la reforma de 1989, porque se regula de modo muy cauteloso, y la experiencia posterior ha sido bastante decepcionante. El referéndum se regula ahora en los diez apartados del art. 156 de la Constitución, aunque de modo restrictivo y, así, se excluyen materias como las enmiendas de la Constitución; se dudaba si cabía el referéndum para la ratificación del nuevo Derecho originario europeo y, además, los referendos portugueses son del tipo exigente y obligan a la participación en ellos de la mayoría absoluta de los censados ${ }^{52}$. Sin embargo, la ola referendaria se levantó

52 Puede consultarse Barbosa Rodrigues, L., O referendo português a nível nacional, Coimbra, Coimbra ed., 1994. 
después de la aprobación de la Ley Orgánica 15-A/1998, de 3 de abril, del régimen del referéndum. El 28 de junio de 1998 se celebró el primer referéndum sobre la despenalización del aborto, que no alcanzó el 15\% de participación. Posteriormente el Gobierno se empeñó en celebrar otros dos: uno, que confirmara la integración de Portugal en Europa en los términos del Tratado de Amsterdam y, otro, que pretendía la regionalización total del Portugal continental, de modo que el país fuera un auténtico Estado regional; por ahora, en tanto no se generalice la regionalización en ciernes, Portugal, sigue siendo un Estado unitario como regla, y excepcionalmente admite dos Regiones autónomas, que son los Archipiélagos de Azores y Madeira ${ }^{53}$. La admisibilidad constitucional del primero de los referendos fue rechazada por el Tribunal Constitucional (Acuerdo del Pleno 531/1998, de 29 de julio) ${ }^{54}$, si bien aceptó la del referéndum acerca de la regionalización (Acuerdo del Pleno 532/1998, de 29 de julio) ${ }^{55}$. En fin, el referendo sobre la regionalización se celebró el 8 de noviembre de 1998 y resultó fallido porque la abstención fue del 51,5\%. Lógicamente, ante esta experiencia, se defraudaron las ilusiones referendarias, se agravaron los síntomas del acusado abstencionismo en la política portuguesa y tuvo que posponerse la exigencia del principio europeo de la subsidiariedad por la falta de los niveles adecuados de adhesión popular. Ya se ha dicho que con la Sexta Reforma se intenta la plena regionalización portuguesa, y conviene añadir que también se generaliza la posibilidad de referendos regionales.

El Gobierno de Santana Lopes estaba estudiando la posibilidad de ratificación popular del PTCR ${ }^{56}$. El nuevo Gobierno Sócrates, en su toma de posesión afirmó que se decidía por un referémdum de ratificación del Tratado Constitucional europeo de Roma que, además, es de suponer que imponga desde arriba el desarrollo facultativo que la des-

53 MirandA, J., lo califica como "Estado unitario regional» (Manual, vol. III, 2. ${ }^{\text {a ed., }}$ p. 243 y ss.).

54 Hay que reconocer el sentido común del TC, pues la portuguesa era una operación mucho más peligrosa que la de los dos referendos irlandeses de 2001 y 2002 sobre el Tratado de Niza, y que la de los últimos referendos en Italia y Francia, de los que ya se ha tratado.

55 Los Acuerdos se reproducen en la página de jurisprudencia del sitio http://tribunalconstitucional.pt. En lo relativo al proyecto de regionalización de 1998, remitimos a MoreIRA, V., "Organizaçião, atribuiçiões, poderes e competencias das Regiões Administrativas", B.F.D, 74, 1998, pp. 657-670, así como a las colaboraciones al respecto en ese mismo número del Boletín de MoREIRA, V., URBANO, M. B., SARMENTO e Castro, C., Sampaio Ventura, C. y Veiga, P., en las pp. 405-555.

56 Cf. El País, Madrid, 28 de julio de 2004, p. 5. 
centralización del País Vecino.... ${ }^{57}$. Esta decisión eufórica de Sócrates se debía a la brillantez histórica de su victoria electoral, no obstante los reveses francés y holandés, según nuestras últimas noticias parece haber disuadido a Portugal de acudir a semejante consulta popular.

\section{ANOMALÍAS ESPAÑOLAS DE LAS REFORMAS Y EN EL MARCO DE CONVERGENCIA CONSTITUCIONAL EN EUROPA}

Después del fallecimiento del autócrata General Franco en noviembre de 1975 accedió a la Corona y a la Jefatura del Estado el Rey D. Juan Carlos de Borbón, que mantuvo como Presidente del Gobierno al señor Arias Navarro. Sin embargo, por su inmovilismo, éste fue cesado y sustituido como Presidente del Gobierno por D. Adolfo Suárez, el cual emprendió, sin ambages, la "transición política española» empezando por la aprobación de la Ley para la Reforma Política de enero de 1977. En junio de 1977, se celebraron las elecciones para el Congreso de los Diputados y el Senado, en las que se demostró una decidida voluntad por acceder a un Estado constitucional y democrático. La redacción del Proyecto de Constitución se encargó a una Ponencia del Congreso, que tuvo ya un anteproyecto en enero de 1978. El texto definitivo del proyecto de Constitución fue aprobado por altas mayorías cualificadas de las dos Cámaras en octubre de ese mismo año. Ratificada después por el pueblo mediante referéndum el 6 de diciembre de 1978, por una mayoría más que suficiente, entró en vigor el 30 de diciembre de 1978. Acerca de este proceso constituyente conviene señalar que se caracterizó por el elevadísimo consenso que únicamente rompieron, al final del proceso, los minoritarios grupos parlamentarios del nacionalismo vasco.

Antes de reemprender la sistemática precedente acerca de la reforma y de la convergencia constitucional, hemos de destacar que, aunque podamos ser breves en la exposición, resulta que estamos ante uno de los más preocupantes problemas jurídico-constitucionales para un armonioso discurrir en la España democrática, como prueba el esfuerzo de alto consenso que supuso la aprobación de la Constitución de 1978 y las consecuencias que se derivaron de ello.

Al igual que en Portugal, en España se dan los requisitos o condiciones de adhesión a la Unión Europea. El Estado español es un Estado

57 El presidente Sócrates hizo el anuncio el sábado 12 de abril (vid., El País del 13 de abril de 2008) en plena euforia de la toma de posesión. 
constitucional de Derecho, regido por el principio de constitucionalidad proclamado en el apartado primero del art. $9 .^{\circ}$ de la Constitución española (en lo sucesivo, CE) ${ }^{58}$. Para asegurar el principio, se dedica un Título a la reforma constitucional, que convierte a nuestra Constitución en rígida, o tal vez demasiado rígida (Título X), y un Título al Tribunal Constitucional, que determina un completo sistema de procedimientos para acceder a su jurisdicción (Título IX). España cumplió el requisito de la adhesión al Convenio Europeo de Roma para la Protección de los Derechos Humanos y de las Libertades Fundamentales en 1979, y cuenta con su propia tradición constitucional, que se remonta a cerca de dos siglos.

Tendremos la oportunidad de comprobar que las manifestaciones de divergencias constitucionales o el ámbito de resistencia constitucional a la integración en España es casi total, de ahí que sean mucho más abundantes las divergencias constitucionales que los elementos de convergencia. La soberanía constitucional en España es acusada; buena prueba de ello es que, en este cuarto siglo de vigencia, únicamente se ha aprobado una reforma de la CE. Así se explican estas divergencias porque, aunque pudiera disponer sobre la forma de la reforma, no lo ha hecho ${ }^{59}$. En cambio, sí ha operado con toda libertad con las fuentes subconstitucionales, tanto para la recepción del Derecho europeo como para evitar la reforma de la Constitución. En cuanto a la constitucionalización de la integración europea, adelantamos que en España es donde se ha producido en menor medida.

58 Este artículo preceptúa que: «Los ciudadanos y los poderes públicos están sujetos a la Constitución y al resto del Ordenamiento jurídico".

59 Queremos advertir que en España la mayoría de la doctrina más autorizada, siguiendo las contribuciones de Merkl, Ross y Crisafulli, no admite como legítima semejante reforma. Así, por ejemplo, DE VEGA, P., La reforma constitucional..., cit., p. 278 y ss.; ARAGón, M., "Problemas actuales de la organización territorial del Estado", Revista de Estudios Políticos (REP), 102, 1998, p. 176; SÁNCHEZ FERRIZ, R., Introducción al Estado Constitucional, Barcelona, Ariel, 1993, p. 272; AlzAGA, O., Derecho Político español según la Constitución de 1978, Madrid, Areces, 1997, vol. I, p. 117; y Balaguer, F., et al., Derecho Constitucional, Madrid, 1999, vol. I, p. 111. Sí la admitía De Otтo, I., Lecciones de Derecho Constitucional, Oviedo, 1980, p.124. Por nuestra parte, también lo acabamos de hacer en "Reconsideración del sistema de reforma de la Constitución española», colaboración en el Libro-Homenaje al Prof. Gumersindo Trujillo (en prensa). 


\subsection{Los procedimientos de reforma constitucional en España}

Las reglas de nuestro sistema de reforma constitucional, se basa en dos procedimientos, condicionados según las materias a reformar: es decir, el procedimiento ordinario del art. 167, que serviría en general para la revisión del articulado de la Constitución; y el procedimiento agravado del art.168, destinado para la reforma total, o para la reforma parcial que afecte al Título preliminar, al Título I, Capítulo II, Sección primera, y al Título II, es decir, el relativo a la Corona. Como también se sabe, en el artículo 167 se exigen mayorías parlamentarias cualificadas, pero puede bastar con la mayoría cualificada del Congreso, y en el apartado $3 .^{\circ}$ se prevé la posibilidad de un referéndum de ratificación si así lo solicita una décima parte de los Diputados del Congreso o de los Senadores. En el artículo 168 se prevé un procedimiento más gravoso, dado que se exige la mayoría cualificada de las dos Cámaras para determinar los principios de la reforma, la disolución de estas Cámaras, la aprobación por la mayoría cualificada de las nuevas Cámaras, y un referéndum de ratificación, en este caso preceptivo u obligatorio.

Acerca de estos procedimientos nos limitamos a hacer algunas observaciones. En primer lugar, que con el procedimiento del 168, a primera vista y teniendo en cuenta únicamente nuestra experiencia histórica republicana semejante, parece que nos hemos convertido en aprendices de brujo, excediéndonos en la ingeniería constitucional, pues queriendo evitar el establecimiento de límites materiales a la reforma a "la portuguesa" que en los setenta eran bastante impopulares, hemos llegado al mismo resultado e incluso más amplio, lo cual ha llevado a opiniones tan autorizadas como la del Prof. Pedro de Vega a mantener que este procedimiento, más que hacer posible la reforma constitucional, parece ideado para impedir la reforma de esas materias; dicho de otro modo, lo que consigue es petrificar la parte protegida de tal modo que la hace en la práctica irreformable o granítica ${ }^{60}$. En segundo lugar, debemos señalar que, tanto en doctrina como entre los operadores jurídico-constitucionales, se aprecia la tendencia a derivar las posibles o hipotéticas reformas que deberían practicarse por medio

60 La reforma constitucional y la problemática del poder Constituyente, Madrid, Tecnos, 1985, p. 148, y parece darle la razón RoDRígUEZ ZAPATA, J., al considerar que "la Constitución de 1978 resulta protegida con la máxima rigidez existente en el derecho comparado" (Teoría y práctica del Derecho Constitucional, Madrid, Tecnos, 1996, p. 225). Por nuestra parte nos limitamos a añadir que hay varios países europeos con un sistema semejante, lo cual no ha sido obstáculo para que revisen con frecuencia su Constitución. 
del artículo 168 hacia el procedimiento más simplificado del 167, lo que se debe, en nuestra opinión, tanto a pretender preservar la duración de su mandato, como a eludir la obligación del referéndum nacional preceptivo de ratificación de los proyectos de nuestros representantes ${ }^{61}$. Y, por último, debemos reconocer que el éxito del consenso constituyente llevó a la doctrina española y a los poderes públicos a mantener que sólo cabía la reforma constitucional cuando se reprodujese ese mismo consenso; de manera que, por mucho tiempo, terminó sacralizándose la Constitución como un libro sagrado intangible para los poderes constituidos, lo que viene a repetir una constante de la historia del constitucionalismo español ${ }^{62}$.

En atención a la dimensión orgánica del sistema español de reforma, hay que empezar señalando que, siendo nuestra forma de gobierno la parlamentaria desde los años treinta del siglo XIX, es lógico que se encomiende la labor revisora a las dos Cámaras de nuestro Cuerpo Representativo. Sin embargo, en el procedimiento ordinario de reforma, de modo semejante a Italia o Francia, se prevé un referéndum facultativo o potestativo para las minorías, y en el procedimiento agravado de reforma, además de someter la misma a dos legislaturas sucesivas, se impone un referéndum preceptivo u obligatorio. En consecuencia, es innegable el carácter democrático de nuestro procedimiento de reforma, pues es posible que la reforma requiera tanto de la democracia representativa como de la democracia directa.

Pensamos que no cabe la fiscalización de la reforma por el Tribunal Constitucional si se ha celebrado el referéndum de ratificación; no obstante, sí es posible mediante dos procedimientos, uno previo a la ratificación y otro posterior a ella, para controlar la constitucionalidad de los Tratados del derecho europeo primario63.

61 Para citar alguna manualística reciente que trata de nuestros procedimientos de reforma constitucional recordamos a BALAGUER, F., Derecho Constitucional (colaboración de F. Balaguer y otros), Madrid, Tecnos, 1999, vol. I, p. 109 y ss.; EsPín TEMPLADO, E., Derecho Constitucional (colaboración de L. López Guerra et al.), Valencia, Tirant lo Blanch, 2002,, vol. I, p. 50 y ss.; y PéRez Royo, J., Curso de Derecho Consti-

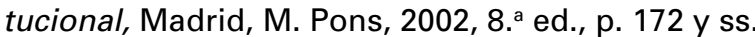

62 Se puede aceptar la tesis de PÉREz Royo, J., de que en nuestros casi dos siglos de historia constitucional la única reforma constitucional ha sido la de 1992 ("Una anomalía española. La aversión a la reforma constitucional», Claves de Razón Práctica, 138, diciembre de 2003, pp. 10-17).

63 El primero de los procedimientos se regula en el art. $95 \mathrm{CE}$, y el segundo en los arts. 162.1 a) y 163 CE y en el art. 27.2 c) de la Ley Orgánica del Tribunal Constitucional, de 1979. 
Asimismo es errática la dimensión formal-instrumental del sistema de reforma español, dado que en el Título X CE no se especificó el tipo de acto normativo de reforma, de manera que en la única revisión practicada se inventó una fuente atípica y extra ordinem denominada "Reforma de la Constitución" y no sería de extrañar que en la próxima reforma se instrumentalizara mediante otra fuente atípica y extra ordinem como la "Revisión de la Constitución».

En la perspectiva sistemático-formal tenemos que reconocer que nuestra Constitución no puede ser incluida entre las que sistematizan las materias relativas a la integración europea en un apartado constitucional, ni es, como la portuguesa, un texto constitucional en el que los enunciados al respecto se dispersan en el articulado de la Constitución. Esta originalidad se desvelará inmediatamente.

\subsection{La excepción española respecto a la convergencia constitucional europea}

Como ha denunciado Häberle ${ }^{64}$, España constituye la excepción frente a la regla tendente a la creación de un Derecho Constitucional Común Europeo mediante la convergencia constitucional, pues, aunque estamos integrados en las Comunidades Europeas desde 1986, en nuestra Constitución no hay ninguna referencia a esa integración ${ }^{65}$.

64 HÄBERLE, P., «El proceso constitucional en Europa», manuscrito de la ponencia del Congreso "25 Años de Constitución Democrática en España», organizado por la Universidad del País Vasco y celebrado en Bilbao durante los días 19-21 de noviembre de 2003 (en prensa), p. 13-14.

65 Una parte de la doctrina entendía que la integración sí estaba presente en el art. $93 \mathrm{CE}$, precepto que habilita a que «mediante ley orgánica se podrán autorizar la celebración de tratados por los que se atribuya a una organización o institución internacional el ejercicio de competencias derivadas de la Constitución..."; y así, en opinión de PÉREZ TREMPS, P., esta cláusula constitucional significa la constitucionalización del proceso de integración europea (Constitución española y Comunidad Europea, Madrid, 1994, p. 36). Nosotros no pensamos así, y la evolución del constitucionalismo español nos ha terminado dando la razón. Es cierto que al principio el precepto se utilizó únicamente para autorizar, mediante sendas leyes orgánicas, la ratificación de la adhesión de España a las Comunidades Europeas, del Acta Única Europea y de los Tratados de Maastricht, Amsterdam y Niza (esta última fue mediante la LO 3/2001, de 6 de diciembre). Sin embargo, desde nuestro punto de vista, no es una cláusula específica para la integración europea, sino, simplemente, una exigencia para la recepción de determinados tipos de tratados, como demuestra la LO 6/2000, de 4 de octubre, que autoriza la ratificación por España del Estatuto de la Corte Penal Internacional, fundamentada en el art. 93, pese a no ser un Tratado de la construcción europea. 
Bien sea por nuestra historia constitucional reacia a la revisión constitucional, o bien se deba a las dificultades procedimentales descritas, o bien sea por la exigencia de un nivel de consenso imposible de alcanzar, lo cierto es que en España en casi un cuarto de siglo únicamente se produjo la reforma constitucional de 1992, de la que hace trece años y por la que se añadió la expresión "y pasivo" al art. 13.2 in fine, de modo que en las elecciones municipales se permiten las candidaturas de los ciudadanos de la Unión Europea, así como de los extranjeros residentes en España con tal de que sus Estados de origen tengan Tratados de reciprocidad al respecto.

Esta lacónica reforma era histórica y jurídico-constitucionalmente bastante relevante. En efecto, es histórica, puesto que en nuestra historia constitucional democrática es la primera de las reformas constitucionales que ha fructificado. $Y$ es relevante por los debates y procesos previos que concluyeron en esos resultados, y porque con su aprobación se alumbró un nuevo tipo de acto o fuente normativa.

No obstante, pese a esa reforma, los contenidos constitucionales de convergencia en España son prácticamente nulos. Si en Portugal empezaron a incorporarse incluso antes de la adhesión, en España, en ese período, únicamente se estableció un precepto en la Constitución de 1978, el art. 93.1, que haría posible esa adhesión y las diversas etapas de la construcción europea. En consecuencia, se puede afirmar que el proceso de integración europeo no está registrado en el nivel constitucional.

Por eso, no se han constitucionalizado cláusulas de cobertura o límites de intangibilidad ante el proceso de integración, ni está constitucionalizado el principio de subsidiariedad. Es cierto que para la adaptación al Tratado de Maastricht se hizo necesaria la reforma de la Constitución en el apartado segundo del artículo 13, para hacer posible el derecho de sufragio pasivo en las elecciones municipales de los ciudadanos de la Unión residentes en España ${ }^{66}$.

66 En la nueva redacción del art., 13.2 modificado por la Reforma Constitucional del 27 de agosto de 1992, se determina que "solamente los españoles serán titulares de los derechos reconocidos en el artículo 23 salvo lo que, atendiendo a criterios de reciprocidad, pueda establecerse por tratado o ley para el derecho de sufragio activo y pasivo en las elecciones municipales". De nuevo estamos ante un precepto de vocación internacionalista y no exclusivamente europeísta, como prueba, por ejemplo, el reconocimiento en España del sufragio pasivo en las elecciones municipales a los ciudadanos de Noruega, que no pertenece a la Unión Europea. Las vicisitudes de esta reforma fueron polémicas e interesantes. La mayoría de la doctrina y el Consejo de Estado entendían que no era preciso reformar el precepto para la ratificación 
La ausencia de otros elementos de convergencia se prueba porque no hay reconocimiento de la democracia paritaria de hombres y mujeres, ni tampoco se han constitucionalizado los procedimientos de participación de las Cortes Generales en la construcción europea, como tampoco la colaboración al respecto de las Comunidades Autónomas ${ }^{67}$, ni se regula en la Constitución nada relativo a la elección de los representantes del Estado español en el Parlamento Europeo ${ }^{68}$. Debemos señalar que tampoco se redimensionan constitucionalmente las atribuciones del Banco de España como consecuencia de la creación del Banco Central Europeo. En el orden jurídico-penal se debe subrayar que la Constitución no determina plenamente la abolición de la pena de muerte $^{69}$, ni se constitucionalizan las consecuencias de la aplicación del Acuerdo de Schengen, ni la Constitución alude a una cuestión sangrante para España como es la represión del terrorismo ${ }^{70}$, ni alude a la

del Tratado; no obstante, el Gobierno, en virtud del art. 95 CE (que, por cierto, también es de vocación internacionalista y no exclusivamente europeísta) planteó un requerimiento mediante el que cuestionaba únicamente si la ratificación del Tratado haría precisa la reforma de la Constitución. El Tribunal Constitucional inauguró este procedimiento constitucional con la Declaración de 1 de julio de 1992, en la que, por fortuna, vino a establecer que el artículo 93 no implicaba un nuevo procedimiento extra ordinem de reforma de la Constitución, puesto que para reformarla sería preciso acudir al procedimiento ordinario de revisión del art. 167 CE.

67 Las Comunidades Autónomas han visto reconocido algún papel en el proceso de integración mediante un Decreto de 1996 que crea la figura de un Consejero (único para todas las Comunidades Autónomas) en el seno de la representación permanente de España ante la Unión Europea. Y la ley 2/1997, de 13 de marzo, regula la Conferencia para asuntos relacionados con las Comunidades Europeas en la que se potencia la participación de las Comunidades Autónomas en el proceso de decisión de las instancias europeas. También algunos Estatutos de Autonomía, como el de Canarias tras la reforma del art. 38, prevén delegaciones españolas ante los órganos comunitarios europeos.

68 En España las elecciones al Parlamento Europeo se regulan, fundamentalmente, en la Ley Orgánica 5/1985, de 19 de junio, de Régimen Electoral General, que fue modificada por la LO 1/1987, de 2 de abril, que para la regularización a las elecciones al Parlamento Europeo añadió un nuevo Título (el VI).

$69 \mathrm{El}$ art. 15 in fine CE proclama que "Queda abolida la pena de muerte, salvo lo que puedan disponer las leyes penales militares para tiempo de guerra». $Y$, en lugar de reformar la Constitución, se aprobó la LO 11/1995, de 27 de noviembre, de Abolición de la pena de muerte en tiempo de guerra. Nuestros reparos a semejante opción normativa no obedecen sólo a razones de estética constitucional, puesto que llegado el tiempo de guerra nadie puede garantizar que no sea derogada esta LO.

70 Es verdad que este agravamiento de las penas se ha producido con sucesivas reformas del Código Penal, así como con recientes leyes orgánicas especiales, como la LO 1/2003, de 10 de marzo, para la garantía de la democracia en los Ayun- 
lucha contra las formas graves de delincuencia ni, en fin, tampoco a la decisión-marco relativa a la orden de detención y entrega europea ${ }^{71}$.

En conclusión parcial, tenemos que reconocer que, frente al activismo generalizado en los Estados miembros en la recepción constitucional de los extremos más relevantes de la Unión Europea, España ha demostrado un absoluto inmovilismo o quietismo, o aversión a la reforma constitucional ${ }^{72}$, por lo que la convergencia se ha producido mediante fuentes subconstitucionales o legales; de lo que resulta la aparición de manifiestas mutaciones constitucionales e, incluso, inconstitucionales ${ }^{73}$.

A pesar de que en España disponemos de un utilísimo mecanismo de Democracia Constitucional en el art. 95 CE por medio del cual el Tribunal Constitucional, con carácter previo a la conclusión del Tratado, puede examinar la compatibilidad de un Convenio in fieri y la Constitución vigente, de manera que se podría evitar la incompatibilidad, renegociando la materia en cuestión, o revisando la Constitución al res-

tamientos y la seguridad de los Concejales, la LO 4/2003, de 21 de mayo, complementaria de la ley de prevención y bloqueo de la financiación del terrorismo y la LO $7 / 2003$, de 30 de junio, de medidas de reforma para el cumplimiento íntegro y efectivo de las penas.

71 En este supuesto, también se acudió a la ley, aprobándose la LO 2/2003, de 14 de marzo, complementaria de la ley sobre la Orden Europea de Detención y Entrega. Y debemos añadir que, una vez entrada en vigor la Decisión de Tampere (el pasado 1 de enero de 2004), el Poder Judicial español se ha significado hasta el momento por ser el que más ha utilizado esta "euroorden». A finales de febrero España se sitúa a la cabeza de la Unión Europea en la puesta en marcha de la "euroorden», puesto que ha planteado la solicitud de setenta y dos órdenes de detención y entrega. Se han ejecutado diecinueve que han acabo en detención, y nueve se han resuelto con la decisión de entrega del delincuente a España (Diario del Derecho, del 23 de febrero de 2004).

72 Hay que subrayar que últimamente en la doctrina constitucionalista existe un clamor en pro de la reforma constitucional, como lo expresa DE VEGA, P., que advierte que la reforma constitucional viene a ser una renovación del poder constituyente, por lo que en España corremos el riesgo de una divergencia entre la Constitución y nuestra democracia ( vid. "Mundialización y Derecho Constitucional: la crisis del principio democrático en el constitucionalismo actual", $R E P, 100,1998$, pp. 46 y $49-50)$. Por su parte, DE CABO, C., ha reclamado la exigencia del cambio democrático de la reforma (La reforma constitucional en la perspectiva de las fuentes del Derecho, Madrid, Trotta, 2003, p. 25).

73 Nos preocupamos de estas cuestiones en «Examen de urgencia de la alternativa entre reforma y mutación constitucional ante la integración europea», en Estudios de Derecho Público. Homenaje a Juan José Ruiz-Rico, Madrid, Tecnos, 1997, vol. I, pp. 299-330, y en el apartado 4 de «Reconsideración del sistema..., cit. 
pecto para que desaparezca la disparidad, el mecanismo, en su práctica, no ha operado como el francés. Si en Francia el Presidente requiere al Consejo Constitucionalidad un pronunciamiento sobre la plena compatibilidad de la totalidad proyecto de Tratado, en la práctica española no se ha impuesto esa generosa atribución, sino que el Gobierno requiere acerca de la compatibilidad de uno o varios preceptos del Tratado con uno o varios preceptos de la Constitución. Pese a tratarse de un procedimiento constitucional especial el Tribunal Constitucional se ha acomodado a esta práctica resaltando su naturaleza jurisdiccional y no de carácter consultivo, y su sometimiento a los principios de congruencia y de conocimiento ex officio. Sucede, además, que a ello se añade que el Consejo de Estado asume la facultad de calificación de los Tratatos, de todos ellos. Y así, en 1992 el Consejo de Estado quiso sentar la doctrina que siendo el Tratado de construcción o de mera integración europea, no sería necesaria la revisión de la Constitución, pues bastaba con lo permitido por el art. 93 CE. El Tribunal respondió señalando que no cabía semejante reforma constitucional extra ordinem, de modo que la discrepancia entre la norma convencional y la norma constitucional debería ser erradicada. Y algo parecido sucedió en 2004 con la autorización de la ratificación del PTCR. Efectivamente, de un lado operó el conocimiento del asunto y de otro del celo de los órganos con respecto a sus competencias, eso se comprueba confrontando la parte dispositiva de ambos actos de fiscalización, porque de nuevo fue preciso acudir a ambos órganos.

Sin embargo, la situación pace haber cambiado últimamente. Se entenderá que eludamos profundizar en esta grave brecha o herida de la pasada democracia constitucional española y, en lugar de ello, hablemos de las novedades más recientes. Después de las tormentosas elecciones del 14 de marzo de 2004, se produjo la alternancia política y el II Gobierno Aznar, que disponía de la mayoría absoluta en las Cortes, tuvo que dar paso a un nuevo Gobierno del Presidente Sr. Rodríguez Zapatero que únicamente cuenta con la mayoría simple del PSOE, pero que consiguió aglutinar el voto de Izquierda Unida y de todos los pequeños partidos nacionalistas o regionalistas. Ya en el discurso programático de la votación de investidura anticipó la reforma de la Constitución, solicitando propuestas al respecto de las otras minorías. Poco después, en una comparecencia institucional a petición propia, el Presidente Rodríguez Zapatero, ante el Senado, concretó que la reforma constitucional consistiría en la modificación de la composición y atribuciones del Senado, en la enunciación constitucional de las 17 Comunidades Autónomas y de las 2 Ciudades autónomas, en la primera referencia constitucional a la integración europea mediante la alusión a 
la llamada "Constitución Europea" y el restablecimiento de la igualdad de Infantes e Infantas en la sucesión a la Corona $^{74}$.

No obstante pronto el diálogo y la apertura a las propuestas se dio cerrado y en efecto, en el 4 de marzo de 2005 se registra el Acuerdo del Consejo de Ministros por el que se encarga al nuevo Consejo de Estado lo siguiente:

«El Consejo de Ministros ha solicitado al Consejo de Estado que emita, antes de finalizar el presente año, un Informe sobre la reforma constitucional, atendiendo a las cuestiones que expresamente se le formulan en relación con las cuatro modificaciones que se pretende introducir en la Constitución.

Anteriormente fue necesario para ello aprobar la Ley Orgánica de 18 de diciembre de 2004, de modificación de la del Consejo de Estado, dotando al Alto órgano consultivo de los instrumentos necesarios para llevar a cabo esta tarea.

Se inicia así la tarea de emprender, desde el diálogo y la participación de todas las fuerzas políticas, una reforma limitada de la Constitución de 1978 que, sin alterar su núcleo fundamental, la acomode mejor a la realidad de la España de hoy.

La propuesta de reforma versa únicamente sobre los cuatro aspectos tasados por el Gobierno: supresión de la preferencia del varón en la sucesión al trono, recepción en la Constitución del proceso de construcción europea, inclusión de la denominación de las Comunidades Autónomas en el texto de la Constitución y, por último, reforma del Senado.

Con el fin de que el Consejo de Estado pueda elaborar su informe con plena autonomía de decisión y con el rigor jurídico y la serenidad que siempre ha caracterizado su funcionamiento, el Gobierno no ha querido adelantar opiniones propias sobre las materias constitucionales que se pretenden modificar y que pudieran ser interpretadas como instrucciones o condicionamientos previos."

Al terminar este trabajo se cumple más de un año de la primera comparecencia del Presidente del Gobierno ante el Pleno del Senado. en la cual al tiempo que presentaba al Gobierno, establecíó los cuatro puntos de reforma constitucional si bien se abría al diálogo y a las propuestas de los demás grupos, aunque ahora, como se ve se han convertido en taxativos. Pasado el año y una vez que se ha superado la

74 Vd. Diario de Sessiones, Senado, del 11 de mayo de 2004. Se podrá observar que la oferta del Gobierno se abre al diálogo y a las propuestas de los demás grupos.

(c) UNED. Revista de Derecho Político 
crisis del "Plan lbarretxe» ${ }^{75}$, son más las sombras que las luces de estas hipotéticas reformas constitucionales.

En primer lugar, porque una reforma como la que se propone, además de premiosa en el tiempo, por tener que discurrir por el art. $168 \mathrm{CE}$, nos da la impresión de que se trata de un señuelo con la finalidad de distraerse con el día a día del gobierno de la política durante dos Legislaturas. Una de las posibles razones de semejante petición al Consejo de Estado es que alguna doctrina ha interpretado que en el apartado $1 .^{\circ}$ del artículo 168 , lo que se debe aprobar y sobre lo que debe acordar por la primera lectura son esos principios (que definiría el Consejo), por lo que se tomarían como base los que determine este último órgano, que luego desarrollará en articulado la siguiente legislatura. Nosotros pensamos que este modo de solicitar consenso es más bien engañoso, pues hubiera bastado un acuerdo del PSOE y del PP (sin cuyo concurso no cabe ningún tipo de reforma constitucional), pero claro está se habrían opuesto las diversas minorías que sostienen al Gobierno. Por el contrario, el Gobierno en lugar de establecer los límites de la reforma constitucional ha permitido que sus aliados en el Gobierno aborden una generalizada reforma estatutaria y de la financiación autonómica en la que al parecer no existe techo constitucional $^{76}$.

Lo que nos parece fuera de toda duda es que esta imprecación gubernamental al Consejo de Estado se debe, tanto a la dificultad del procedimiento del art. $168 \mathrm{CE}$, como a la imposibilidad de llegar a un acuerdo con el PP al mismo tiempo que a un consenso en el seno de una mayoría abigarrada y heterogénea. Francamente, el talante inicialmente dialogante del Gobierno de Rodríguez Zapatero nos recuerda mucho la propuesta pluralista del método de interpretación de Häberle de la "constitución abierta» ${ }^{77}$. De cualquier modo, da un penosa im-

75 No sin recelo hablamos de superación del Plan lbarretxe, pero es lo que cabe deducir de la información periodísticamente divulgada (El País, del 6 y del 7 de mayo de 2005).

76 Nos pasaría así como en la II República en la que primero se aprobó el proyecto de Estatuto del Estàt català que la Constitución de la República, de manera que se produjeron dos efectos: primero, el proyecto de Estatuto condicionó el proceso constituyente y, segundo, fue muy difícil reconducir las exigencias autonomicas catalanas a lo que la Constitución de 1931 permitía.

77 Se recordará que este método preconiza una interpretación ultra-democrática de la Constitución mediante el máximo consenso de los sujetos públicos y privados (HÄBERle, P., Pluralismo y Constitución. Esudios de Teoría Constitucional de la sociedad abierta, Madrid, Tecnos, 2002, p. 86 y ss). El nuevo Gobierno español, como 
presión esta modalidad de dirección, orientación o impulso político por las fuerzas mayoritarias. Por eso en otras ocasiones hemos sugerido la supresión o aliviamiento procesal del art. $168 \mathrm{CE}$.

$Y$ no parece que la etapa inaugurada con el referéndum del domingo 20 de febrero de 2005, aunque representa un hito importante de la participación de los gobernados en la construcción de Europa (después de 20 años de la adhesión), se limitara a la aceptación o no de la Constitución Europea, pero no se prevé un reforma constitucional que sistematice en un apartado ad hoc todas las conquistas alcanzadas al respecto en la constitucionalización de la convergencia por los demás Estados miembros de la Unión y de lo que da una buena idea la comparación con las seis reformas constitucionales portuguesas. Creemos que ello se debe a la utilización pacata del art. 95 CE y a otros índices ${ }^{78}$. De modo que se presume que por la prontitud del referéndum nos convertimos en adalides de Europa, pero, en realidad, por los defectos criticados somos los más retrasados en términos jurídico-constitucionales, es decir de una reforma constitucional que incorpore los precisos elementos de convergencia. Mientras no se haga así, seguiremos manteniendo nuestro proverbial e hispánico repudio de las reformas constitucionales y considerando a la Constitución como un libro sacralizado por el consenso, que cada vez se va quedando más aislado de la realidad constitucional española y de la normatividad de nuestros consocios europeos.

se demuestra, ha utilizado ese método de apertura en cuanto a las reformas de la Constitución y en lo referente a las reformas estatutarias únicamente ha exigido consenso y respeto a la Constitución, pero cuando hay que tomar la resolución se impone la perspectiva del PSOE, de modo que si se quiere que estas reformas prosperen y no se queden en mero señuelo será preciso contar con la opinión y el apoyo del PP.

78 El apresuramiento también se ha puesto en evidencia con la aprobación mediante los precedimientos de urgencia y de lectura única de la Ley Orgánica 1/2005, de 20 de mayo, por la que se autoriza la ratificación por España del Tratado por el que se establece una Constitución para Europa, firmado en Roma el 29 de octubre de 2004. En dicha Ley se contiene una Exposición de Motivos que recuerda a un «catecismo europeísta» del PTCR y un artículo único de ratificación, cuando lo más aconsejable hubiera sido esperar a la consulta al Consejo de Estado de modo que indicara en qué sentido debería ser remozada nuestra Constitución para alcanzar una media razonable de convergencia constitucional europea e incorporarla ya a la Ley Orgánica, en espera de la reforma de la Constitución, introduciendo los límites de intangibilidad, el papel de las Cortes Generales y de las Comunidades Autónomas, por ejemplo. 


\subsection{Los referendos españoles en el último cuarto de siglo}

Tampoco es muy lograda la política referendaria de los poderes constituidos después de aprobada la Constitución, el primer referéndum porque se sometió al poder de los cañones y sólo el segundo pudo atender al apetito de la mantequilla.

Se debe recordar que la cuestión del referéndum fue uno de los temas centrales del debate constituyente y que en el Anteproyecto de Constitución se habían previsto tres modalidades: a) un referéndum abrogativo para derogar leyes vigentes (como en el precedente republicano español -art. 66- y como el referéndum abrogativo italiano del art. $75 \mathrm{CRI}$ ); b) un referéndum legislativo de ratificación de proyectos de ley todavía no sancionadas por el Jefe del Estado (semejante a la modalidad de referéndum previsto en el art. 11 de la Constitución francesa de 1958); y c) un referéndum facultativo para decisiones políticas de especial transcendencia y no necesariamente vinculadas a un procedimiento legislativo (como el previsto en el art. 51 de la Ley para la Reforma Política de $1976^{79}$ ). No obstante, después del debate constituyente sólo se admitió como modalidad este último tipo de referéndum que es el que se contempla en el art. $92 \mathrm{CE}$. Con lo que se ha visto hasta ahora, se deduce que las técnicas de Democracia directa admitidas en nuestra Constitución son muy escasas y, en todo caso, concebidas exclusivamente como complemento de la planta básica de la Democracia representativa que define casi en su totalidad nuestro Estado democrático.

El referéndum del art. 92 CE acerca de las decisiones políticas de especial transcendencia es de carácter facultativo o potestativo y su fuerza vinculante es sólamente consultiva. En términos técnico-jurídicos, el referéndum no vincula jurídicamente, si bien, en términos jurídico-políticos una decisión mayoritaria del Pueblo en ningún caso debería ser desatendida por los poderes públicos. En cuanto a su regulación el art. 92.2 CE establece que el referéndum será convocado por el Rey (como un acto debido), mediante propuesta del Presidente del Gobierno, previamente autorizada por el Congreso de los Diputados.

79 «El Rey podrá someter directamente al pueblo una opción política de interés nacional, sea o no de carácter constitucional, para que decida mediante referéndum, cuyos resultados se impondrán a todos los órganos del Estado. Si el objeto de la consulta se refiriera a materia de competencia de las Cortes y éstas no tomaran la decisión correspondiente de acuerdo con el resultado del referéndum, quedarán disueltas, procediéndose a la convocatoria de nuevas elecciones". 
Hasta 2005, en aplicación de la previsión constitucional del art. 92 la única decisión política sometida a referéndum de los españoles fue la de la permanencia en la alianza militar de la OTAN que se celebró el 12 de marzo de 1986. En esta consulta el Censo de electores era de 29.025 .494 y votaron 17.246 .756 , lo que representó un $59,42 \%$ de participación y un $40,58 \%$ de abstención. Votaron a favor de una permanencia condicionada 9.054.509 (52,50\%), en contra $6.872 .421(39,85 \%)$, los votos en blanco fueron $1.127 .676(6,54 \%)$ y los nulos $191.855(1,11 \%)$.

Podría pensarse que en rectificación de un pasado despectivo con el pueblo porque se le consideraba únicamente competente para votar cada cuatro años, o también pudiera interpretarse como un remate sibilino a lo que ocurrió el 14 de marzo de 2004, lo cierto es que el Presidente Rodríguez Zapatero para distanciar su política de la del Presidente Aznar, nos sorprendió a todos con la convocatoria de un referéndum del tipo del art, 92 y que venía a expresar una entusiástica adhesión a la Europa Ampliada y al Tratado Constitucional para el establecimiento de una Constitución para Europa firmado en Roma (PTCR). No obstante, antes de la consulta popular hizo dos requerimientos al Consejo de Estado y al Tribunal Constitucional.

El Consejo de Estado evacuó el 21 de octubre de 2004, con el lacónico decissum del Dictamen que sigue:

"Y, en mérito de lo expuesto, el Consejo de Estado es de dictamen:

Que la prestación del consentimiento del Estado para obligarse en virtud del Tratado por el que se establece una Constitución para Europa requiere autorización de las Cortes Generales mediante ley orgánica aprobada al amparo del artículo 93 de la Constitución. 2. Que, con carácter previo a la ratificación, es conveniente que se haga uso de la facultad prevista en el artículo 95.2 de la Constitución para que el Tribunal Constitucional declare si existe o no contradicción entre el Tratado por el que se establece una Constitución para Europa y la propia Constitución española.

V.E., no obstante, resolverá lo que estime más acertado.»

Por el contrario, el TC resulta evidente que se tomó más en serio su competencia y si bien el fallo de la Declaración 1/2004 no fue más retórico, la mayoría no estaba dispuesta a continuar por el mismo camino. Así en el fallo de la breve Declaración ${ }^{80}$ del 13 de diciembre de 2004 el Tribunal informó:

80 La calificamos de breve pues de las 21 páginas de la Declaración, 8 son de antecedentes, 6 de Fundamentos jurídicos y las otras 7 se ocupan por sendos Votos Particulares. También empieza a sorprender las diversas ocasiones en las que el 
1. ${ }^{\circ}$ Que no existe contradicción entre la Constitución española y el atículo I-6 del Tratado por el que se establece una Constitución para Europa, firmado en Roma el 29 de octubre de 2004.

2. Que no existe contradicción entre la Constitución española y los arts. II-111 y II-112 de dicho Tratado.

3. ${ }^{\circ}$ Que el art, 93 de la Constitución española es suficiente para la prestación del consentimiento del Estado al Tratado referido.

4. ${ }^{\circ}$ Que no procede hacer declaración alguna en cuanto a las preguntas del Gobierno»

Esta Declaración, pese a lo limitado de su alcance de confrontación, fue apresurada, muy discutida y a la cual se presentaron tres Votos Particulares de los Magistrados. No obstante, el Gobierno, una vez expedito el recorrido jurídico (con la Declaración del Tribunal Constitucional) y los avatares políticos con la estrecha victoria referendaria) parece haberse extraviado y enselvado un poco, en lo que a la anunciada reforma de la Constitución respecta.

Los resultados del referéndum no fueron esplendorosos y han amenazado a los resultados de referendos preceptivos o facultativos en otros Estados (puesto que la premura de un Estado receptor ha podido generar suspicacias en los Estados contribuyentes netos). En concreto, de un Censo de 33,5 millones de electores, rehusaron a hacerlo el $24,6 \%$ y de los votantes se mostraron a favor del Tratado el $76,7 \%$ y manifiestamente en contra el $6,03 \%$. Antes de juzgar estos resultados que nos llevarían a la discusión del acierto de la premura del Presidente español, preferimos recordar que los fracasos refrendarios en Francia y Holanda de mayo y junio han motivado una paralización que debía resolver el Consejo Europeo de Bruselas del 16-17 de junio, pero parece que no lo ha conseguido pues ha cundido el europesimismo, que la "presidencia inglesa" no contribuye a despejar y, en España, seguimos empantanados con nuestras cuitas internas que se han antepuesto indebidamente al consenso básico sobre las reformas constitucionales.

Consejo Constitucional francés ha encontrado incompatibilidades entre los Tratados y la Constitución y que nuestro Tribunal Constitucional únicamente apreciara el del art. 13.2. Concluyendo este apartado quisiéramos reconocer que SolozABÁL ECHEVARRÍA, J. J., también se ha ocupado de estas cuestiones especialmente en el apartado III de "El Tratado constitucional europeo y la reforma de nuestra Constitución» en Revista Galega de Administración Pública, manuscrito pendiente de publicación en un próximo número monográfico. 